\title{
MCP1 Directs Trafficking of Hematopoietic Stem Cell-Derived Fibroblast Precursors in Solid Tumor
}

\author{
Romeo S. Abangan, Jr., ${ }^{* \dagger \neq}$ \\ Christopher R. Williams, ${ }^{* \dagger}$ Meenal Mehrotra, ${ }^{* \dagger}$ \\ James D. Duncan, ${ }^{* \dagger}$ and Amanda C. LaRue ${ }^{\star \dagger \S}$ \\ From the Department of Veterans Affairs Medical Center," the \\ Department of Pathology and Laboratory Medicine, ${ }^{\dagger}$ the College \\ of Pharmacy, ${ }^{*}$ and the Hollings Cancer Center, $\$$ Medical \\ University of South Carolina, Charleston, South Carolina
}

Our previous studies have demonstrated that hematopoietic stem cells (HSCs) are a novel source of carcinoma-associated fibroblasts. However, the mechanisms regulating recruitment and homing of HSC-derived carcinoma-associated fibroblasts or their precursors to the tumor microenvironment are unknown. Herein, we demonstrate using a single cell transplantation model that circulating fibroblast precursors (CFPs) are of HSC origin. This population increased with tumor burden in vivo and functional in vitro studies showed that CFPs preferentially migrated and differentiated into fibroblasts in response to tumor, suggesting that HSC-derived CFPs serve as an intermediate between the bone marrow and tumor. Based on this chemotactic ability and our demonstration of a monocyte lineage origin for CFPs, we investigated the role of monocyte chemoattractant protein (MCP1) in mediating CFP recruitment/homing. Blocking tumorproduced MCP1 inhibited in vitro migration of CFPs in response to multiple tumor types, indicating broad biological significance for this CFP/chemokine interaction. In vivo, CCR2-expressing CFPs increased in circulation during the period of active tumor growth and stromal development. Inhibition of MCP1 during tumor development resulted in decreased tumor volume in tumor-bearing mice. Together these findings confirm an HSC origin for CFPs, demonstrate a role for MCP1 in regulating their contribution to the tumor microenvironment, and suggest a potential therapeutic target for limiting tumor growth. (Am J Pathol 2010, 176:1914-1926; DOI: 10.2353/ajpath.2010.080839)

Recent studies have shown that the tumor stromal microenvironment co-evolves with tumor and suggest that the tumor-stroma interaction holds exciting potential as a therapeutic target. One of the most prevalent stromal components of solid tumors is the fibroblast, termed carcinoma-associated fibroblasts (CAFs). Only recently have CAFs been appreciated for their potential ability to promote tumor progression, ${ }^{1,2}$ by stimulating growth of the cancer cell population, sustaining vascularization, inhibiting the immune response, and promoting invasion and metastasis. ${ }^{3-7}$ While the importance of the CAFs is becoming evident, the source of these cells is less clear. It was generally thought that all stromal fibroblasts were recruited from resident tissue fibroblasts. Recently, alternative sources for CAFs have been proposed. Several studies have suggested that fibroblasts/myofibroblasts in fibrotic lesions and tumors may arise from transdifferentiation of epithelial cells to myofibroblasts, a process termed epithelial-to-mesenchymal transdifferentiation. ${ }^{8-10}$ While a rare event, because epithelial-to-mesenchymal transdifferentiation-derived CAFs are thought to retain genetic and/or epigenetic insults of the tumor cell progenitor, it is thought that these cells have a distinct behavioral and molecular signature from CAFs of other origins. ${ }^{10}$ Recent studies have also suggested that CAFs may have a bone marrow (BM) origin. ${ }^{5-7,11}$

Adult bone marrow is thought to contain at least two types of stem cells, hematopoietic stem cells (HSCs) and mesenchymal stem cells (MSCs). HSCs are defined by their ability to repopulate the bone marrow and blood lineages of lethally irradiated mice. MSCs are a population of bone marrow cells that were defined in vitro based on their adherent properties ${ }^{12,13}$ and later by their ability to give rise to a variety of mesenchymal cell types including adipocytes, ${ }^{14,15}$ chondrocytes, ${ }^{14,16,17}$ osteoblasts/osteocytes, ${ }^{14,18}$ endothelial cells, ${ }^{19}$ and fibroblasts. ${ }^{20}$ Based on their adherent properties and their ability to give rise to mesenchymal cell types, it is widely held that the bone marrow source of fibroblasts is the MSCs. However, recent studies by our group have raised the intriguing

Supported by the office of Research and Development, Medical Research Services, Department of Veterans Affairs to A.C.L. and the American Cancer Society Institutional Research grant (IRG 97-219-08 to A.C.L.).

Accepted for publication December 9, 2009.

Address reprint requests to Amanda C. LaRue, Ph.D., Ralph H. Johnson VA Medical Center, 109 Bee Street, Charleston, SC, 29401. E-mail: laruerc@musc.edu. 
possibility that HSCs also give rise to fibroblasts. Our studies using clonally engrafted animals in which the bone marrow is reconstituted by a clonal population of cells derived from a single enhanced green fluorescent protein-positive $\left(\mathrm{EGFP}^{+}\right) \mathrm{HSC}$ demonstrated an HSC origin for two types of fibroblasts precursors, bone marrow colony forming unit fibroblasts and circulating fibrocytes. ${ }^{21}$ Using these clonally engrafted mice, we have also established an HSC origin for multiple tissue fibroblasts (reviewed $\mathrm{in}^{22}$ ), including those found in the tumor stroma. ${ }^{23}$

Based on our previous studies demonstrating an HSC origin for at least a portion of $\mathrm{CAFs},{ }^{23}$ herein, we tested the hypothesis that an HSC-derived circulating fibroblast precursor (CFP) is recruited from the bone marrow to the tumor microenvironment. Using a single cell transplantation model in conjunction with the Lewis lung carcinoma model (LLC), our findings demonstrate that CFPs are of HSC origin. We also show that CFPs increase in the peripheral blood with tumor burden and contribute to tumor stroma formation in vivo. Functional in vitro studies show that CFPs preferentially migrate and differentiate to fibroblasts in response to tumor. To elucidate the mechanisms by which these cells are recruited to tumor microenvironment, we examined the role of chemokines with known roles in HSC and/or tumor biology including CXCL12 (stromal-derived factor-1), CCL21 (secondary lymphoid chemokine) and MCP1/CCL2 (monocyte chemotactic protein; MCP1). The stromal-derived factor-1 pathway has been shown to be a major mediator of cell trafficking in both $\mathrm{HSC}^{24}$ and tumor biology ${ }^{25}$ and fibrocytes have been shown to express the stromal-derived factor-1-receptor, CXCR4. ${ }^{26,27}$ CCR7, the major receptor for secondary lymphoid chemokine, is also expressed by $\mathrm{HSCs}^{28}$ and was the first chemokine receptor shown to be expressed on fibrocytes. ${ }^{26}$ Hematopoietic progenitor cells, ${ }^{28}$ monocytes/ macrophages ${ }^{29}$ and fibrocytes in lung fibrosis ${ }^{30}$ have been shown to express the MCP1 receptor, CCR2. Our data demonstrate that HSC-derived CFP recruitment to the tumor microenvironment is mediated by MCP1/CCR2. These studies also show that disruption of the MCP1/CCR2 axis in tumor-bearing animals leads to reduced tumor burden. Together, these studies identify a novel HSC-derived CFP source and demonstrate a role for MCP1 in early stages of solid tumor formation with respect to its ability to regulate HSC-derived CFP participation in tumor microenvironment.

\section{Materials and Methods}

\section{Mice}

C57BI/6-CD45.1 breeders were purchased from Jackson Laboratories (Bar Harbor, ME). Transgenic EGFP breeding pairs (C57BI/6-CD45.2 background) were provided by Dr. Masaru Okabe (Osaka University, Japan). ${ }^{31}$ Mice were bred and maintained at the Animal Research Facility of the Veterans Affairs Medical Center (Charleston, SC). Research was conducted in accordance with guidelines set by the PHS Policy on Humane Care and Use of Laboratory Animals and the Institutional Animal Care and
Use Committee, Department of Veterans Affairs Medical Center.

\section{Antibodies and Reagents}

The following were purchased from BD Pharmingen (San Jose, CA): phycoerythrin (PE)-conjugated anti-Sca-1 (antiLy-6A/E[D7]); allophycocyanin (APC)-conjugated anti-c-kit (2B8); biotinylated and fluorescein isothiocyanate-conjugated anti-CD34 (RAM34); PE-conjugated, biotinylated, or purified anti-Gr-1 (anti-Ly-6G[RB6-8C5]); PE-conjugated or biotinylated anti-CD45R/B220 (RA3-6B2); PEconjugated anti-Thy-1.2 (30-H12); biotinylated or purified anti-TER-119; biotinylated anti-CD3e, PE and APC-cyanine (Cy7)- conjugated anti-CD45 (Leukocyte Common Antigen, Ly-5;30-F11); PE and fluorescein isothiocyanate-conjugated anti-Mac-1 (CD11b; M1/70); PE-conjugated and biotin-conjugated anti-CD8a (53-6.7); PE-conjugated and biotin-conjugated anti-CD4 (GK1.5); and PE-conjugated anti-CD45.1 (A20). PE-conjugated antiF4/80 (BM8), and fluorescein isothiocyanate-, APC-, and biotin-conjugated anti-CD34 (RAM34) were obtained from eBioscience (San Diego, CA). Discoidin domain receptor 2 (DDR2) goat polyclonal antibodies were purchased from Santa Cruz Biotechnology (Santa Cruz, CA). Biotin-conjugated purified anti-collagen type 1 (rabbit) antibody (Col-1; BAC) and biotin-conjugated Rabbit IgG whole molecule was purchased from Rockland Immunochemicals (Gilbertsville, PA). Purified rabbit monoclonal CCR2 antibody (CCR2; E68) and antibodies to vimentin were purchased from Abcam (Cambridge, MA). Antibodies to $\alpha$-smooth muscle actin ( $\alpha$-SMA) were obtained from Sigma (St. Louis, MO) and Abcam. MCP1/CCL2 neutralizing antibody was purchased from R\&D Systems (Minneapolis, MN). PE-conjugated, APC-conjugated, Cy-5- and Cy3-conjugated secondary antibodies were purchased from Jackson ImmunoResearch (West Grove, PA).

\section{Transplantation}

Ten- to fourteen-week-old male or female EGFP mice were used as donors. Clonal cell transplantation was performed using previously described methods with minor modifications. ${ }^{21,23}$ Bone marrow cells were flushed from femurs and tibiae, pooled, and washed in PBS containing $0.1 \%$ bovine serum albumin (BSA). Mononuclear cells were isolated by gradient separation using Lympholyte M (Cedarlane Laboratories Limited, Ontario) and lineage-negative (Lin-) cells were prepared by negative selection using biotin-conjugated antibodies (anti-B220, -Gr-1, -CD4, -CD8, -TER-119) and MACS anti-biotin microbeads (Miltenyi Biotec Inc, Auburn, CA). Lin- cells were stained with PE-conjugated anti-Sca-1, APC-conjugated anti-c-kit, and biotinylated anti-CD34 followed by streptavidin-conjugated APC-Cy7 and resuspended $(1 \times$ $10^{6}$ cells $/ \mathrm{ml}$ ) in $\mathrm{Ca}^{2+}$-, $\mathrm{Mg}^{2+}$-free Hanks balanced salt solution (Invitrogen, Gaithersburg, MD) with 2\% fetal bovine serum (FBS; Atlanta Biologicals, Lawrenceville, GA), $10 \mathrm{mmol} / \mathrm{L}$ HEPES, and $1 \%$ penicillin/streptomycin. Cells were then incubated with Hoechst 33342 (Sigma; 5 mg/ 
$\mathrm{ml}$ ) at $37^{\circ} \mathrm{C}$ for 60 minutes. After washing, propidium iodide was added and cell sorting was performed using a MoFlo Fluorescence Activated cell sorter (Dako Cytomation, Fort Collins, CO). The gate used for side population cells corresponded to R3 and R4 subfractions described by Goodell et $\mathrm{al}^{32}$ and R1 and R2 described by Matsuzaki et al. ${ }^{33}$ Single Lin ${ }^{-}$Sca$1^{+} \mathrm{Ckit}^{+} \mathrm{CD} 34^{-}$side population cells were deposited into wells of Corning U-bottom 96-well culture plates (Corning, NY) using the CyCLONE cell deposition system. Eighteen hours after single-cell deposition, wells containing single cells were identified and the incubation continued for a total of 7 days at $5 \% \mathrm{CO}_{2}, 37^{\circ} \mathrm{C}$ in media containing $\alpha$ modification of Eagle's medium (ICN Biomedicals, Aurora, OH), 20\% FBS, $1 \%$ deionized fraction $\mathrm{V}$ BSA, $1 \times 10^{4} \mathrm{~mol} / \mathrm{L}$ 2-mercaptoethanol (Sigma), 100 $\mathrm{ng} / \mathrm{ml} \mathrm{SCF}$, and $10 \mathrm{ng} / \mathrm{ml} \mathrm{G-CSF}$. This combination of cytokines stimulates proliferation of primitive hematopoietic progenitors. ${ }^{34}$ Because the majority of HSCs are dormant in cell cycle and begin cell division a few days after initiation of cell culture, we selected clones consisting of no more than 20 cells after incubation. This method significantly enhanced the efficiency of generating mice with high-level multilineage engraftment. ${ }^{21,23}$ Approximately one-fourth of all mice transplanted using these methods resulted in high-level multilineage engraftment above $50 \%$.

Recipient C57BI/6-CD45.1 mice (10- to 14-week-old) were given a single 950-cGy dose of total-body irradiation using a $4 \times 10^{6} \mathrm{~V}$ linear accelerator. Contents of wells ( $\leq 20$ clonal cells) were injected via tail vein into lethally irradiated mice with $500 \mathrm{CD}^{4} 5.1\left(\mathrm{EGFP}^{-}\right)$bone marrow $\mathrm{Lin}^{-} \mathrm{ckit}^{+} \mathrm{Sca}-1^{+} \mathrm{CD} 34^{+}$radioprotective cells. Osawa et al ${ }^{35}$ showed that these $\mathrm{CD} 34^{+}$cells are effective radioprotective cells and contain almost no HSCs.

For generation of mice transplanted with unmanipulated bone marrow cells, bone marrow was flushed, washed, and prepared from EGFP mice as described above. One million white blood cells were delivered to lethally irradiated C57BI/6-CD45.1 mice as described.

For hematopoietic engraftment analysis, peripheral blood was obtained from the retro-orbital plexus of anesthetized mice and red blood cells were lysed $(1 \times$ PharM Lyse; BD Pharmingen). Donor-derived cells $\left(\mathrm{EGFP}^{+}\right)$in T cell, B cell, granulocyte, and monocyte/macrophage lineages were analyzed by staining with $\mathrm{PE}$-conjugated anti-Thy-1.2, anti-CD45R/B220, anti-Gr-1, and antiMac-1, respectively. Mice with total engraftment levels below $50 \%$ were not used for studies.

\section{CFP Sorting}

Peripheral blood (1.5 to $2 \mathrm{ml}$ ) was obtained via cardiac puncture from isoflurane-anesthetized mice using a $281 / 2$ gauge syringe resulting in euthanasia by exsanguination. Samples were then lysed (BD PharM Lyse) for 15 minutes, washed in PBS containing DNase (Invitrogen, Carlsbad, CA) and blocked with normal goat serum (Jackson ImmunoResearch) for 20 minutes at $4^{\circ} \mathrm{C}$. Cells were stained using optimum concentrations of primary antibodies for 20 minutes at $4^{\circ} \mathrm{C}$, washed and incubated with appropriate secondary antibodies for 20 minutes at $4{ }^{\circ} \mathrm{C}$. Samples were analyzed and/or sorted using a MoFlo high-performance cell sorter.

\section{Cell Lines}

Murine Lewis lung carcinoma (LLC 1), mammary carcinoma (EMT6), osteosarcoma (K7M2) and mouse lung epithelial (MLE-12) cell lines were obtained from American Type Culture Collection (Manassas, VA) and propagated and harvested using standard cell culture methods. All cells were grown to $95 \%$ confluency in $5 \% \mathrm{CO}_{2}$, $37^{\circ} \mathrm{C}$. LLC and K7M2 cells were cultured in Dulbecco's Modified Eagle medium (DMEM; Invitrogen) containing 10\% FBS. EMT6 cells were grown in Waymouth's MB 752/1 Media with $2 \mathrm{mmol} / \mathrm{L}$ L-Glucose (Invitrogen) containing 15\% FBS. MLE-12 cells were cultured in 50:50 DMEM: Ham's F12 Media (Sigma) containing 2\% FBS and insulin-transferrin-sodium selinite media supplement (Sigma).

For injection into mice, recovered LLC cells were resuspended in serum-free medium at a concentration of $1 \times 10^{6}$ cells $/ 0.2 \mathrm{ml}$ and injected subcutaneously into anesthetized engrafted mice. Tumor length and width was measured daily to calculate tumor size $(L \times W)$.

\section{Migration Assays}

Migration assays were performed using $8.0 \mu \mathrm{m}$ pore size Costar Transwell inserts (Corning) according to the manufacturer's protocol. Peripheral blood, sorted CFPs or control MLE-12 cells were resuspended at $1 \times 10^{7}$ cells $/ \mathrm{ml}$ in DMEM containing 10\% FBS. Experimental wells received $600 \mu \mathrm{l}$ of 24-hour conditioned tumor cell media (LLC-CM, EMT6-CM, or K7M2-CM), or CM with the addition of $4.5 \mu \mathrm{g}$ neutralizing antibodies to MCP1 and control wells received $600 \mu$ l DMEM containing $10 \%$ FBS. Transwell inserts were placed and peripheral blood cells, sorted CFPs or control MLE- 12 cells were added in 200 $\mu l$. After a 3-hour incubation at $37^{\circ} \mathrm{C}$ in $5 \% \mathrm{CO}_{2}$, migrated cells were recovered from the lower well using TrypsinEDTA $0.25 \%$ and counted. Experiments were conducted with four to six replicates using four mice per replicate.

\section{Culture of Sorted CFPs}

Sorted CFPs were grown in human fibronectin coated 4- or 8-well culture slides (BD Biosciences, San Jose, CA) at $37^{\circ} \mathrm{C}$ in $5 \% \mathrm{CO}_{2}$ for up to 14 days. Experimental wells received 24-hour tumor-CM, or tumor-CM containing $4.5 \mu \mathrm{g}$ of neutralizing MCP1 antibody. Control wells received 10\% FBS/DMEM (control), 10\% FBS/DMEM containing 10\% mouse serum (Equitech-Bio, Kerrville, TX), or tumor-CM alone (without sorted cells added to well). In some experiments, macrophage-colony stimulating factor (M-CSF; R\&D Systems) was added to CFP cultures at $10 \mu \mathrm{g} / \mathrm{ml}$.

\section{Enzyme-Linked Immunosorbent Assay}

Enzyme-linked immunosorbent assay (ELISA) was performed on 24-hour conditioned cell culture supernatants 
using R\&D Systems Quantikine ELISA kits (R\&D Systems) according to the manufacturer's protocol and analyzed with a SPECTRAmax M2 microplate reader running SoftMax Pro software (Molecular Devices, Sunnyvale, CA).

\section{Immunohistochemistry and Microscopy}

Cultured cells were fixed in 4\% paraformaldehyde for 20 minutes and tumor tissues were fixed in $4 \%$ paraformaldehyde for 6 hours. Tumors from engrafted mice were processed for paraffin sectioning as previously described using protocols that allow for preservation of fluorescence intensity. ${ }^{23,36}$ For staining, samples were permeabilized in $0.01 \%$ Triton X-100/PBS (15 minutes), blocked in 3\% BSA $/ 5 \%$ normal donkey serum/PBS (2 hours), and incubated with appropriate primary antibodies diluted in 3\% BSA $/ 5 \%$ normal donkey serum/PBS (1 hour). Samples were washed in PBS and incubated for 1 hour with fluorochrome-conjugated secondary antibodies diluted in 3\% BSA $/ 5 \%$ normal donkey serum/PBS. The samples were again washed in PBS, incubated with Hoechst 33342 nuclear dye (diluted 1:20,000 in PBS; 8 minutes), washed in PBS and coverslipped. Epifluorescence and differential interference contrast (DIC) microscopy was conducted using a Leica DMR microscope with a narrow band-pass green fluorescent protein excitation cube. Images were processed using Adobe Photoshop CS2 (Adobe Systems, Inc., San Jose, CA).

\section{Quantitative Real-Time PCR Analysis}

Cells were sorted using the MoFlo cell sorter. Total RNA was extracted from sorted cells using TRIZOL (Invitrogen) following the manufacturer's instructions. Two $\mu \mathrm{g}$ of total RNA was converted to cDNA by the High Capacity cDNA Reverse Transcription Kit (Applied Biosystems, Foster City, CA) following company recommended protocol. Quantitative real time PCR analysis (QPCR) was performed for different genes in separate wells (singleplex assay) of 96-well plate in a reaction volume of $20 \mu \mathrm{l}$. Predesigned unlabeled gene-specific PCR primers and TaqMan dye-labeled probes (Assays-on-Demand Gene Expression mix) were purchased from Applied Biosystems. Glyceraldehyde-3phosphate dehydrogenase served as the endogenous control for all experiments. Three replicates of each sample were amplified to give one measurement for a sample. Primers were tested for equal efficiency over a range of target gene concentration before use. All primers were designed to cross exon-exon boundaries. The PCR reaction mixture (including 2x TaqMan Gene Expression Master Mix, 20x Assays-on-Demand Gene Expression Assay Mix, $100 \mathrm{ng}$ of (DNA) was run in Applied Biosystems ABI Prism 7500 Sequence Detection System instrument using universal thermal cycling parameters. The relative quantification of target gene expression in a test sample to a control calibrator sample ( $\Delta \Delta$ Ct Method) was used for data analysis.

\section{Inhibition of CFP Trafficking in Vivo}

C57BI/6-CD45.1 mice were subcutaneously injected with LLC cells as described above. Half of the mice received
MCP1 neutralizing antibody (66 $\mu \mathrm{g} /$ mouse; stock $1 \mu \mathrm{g} /$ $\mathrm{ml}$ ) via tail vein injection on days $2,4,6,8,10,12,14$, and 16 after tumor cell delivery. This dose was based on ELISA studies of MCP1 production by LLC cells. Mice were euthanized on day 18 of tumor growth. Tumor volume was calculated using the ellipsoid volume formula $(\pi / 6 \times L \times$ $\mathrm{W} \times \mathrm{H}){ }^{37}$ Tumors were then divided into two samples, one half was fixed and processed for paraffin sections and the other half was digested overnight with trypsin-EDTA $0.25 \%$, then stained and analyzed using the MoFlo cell sorter.
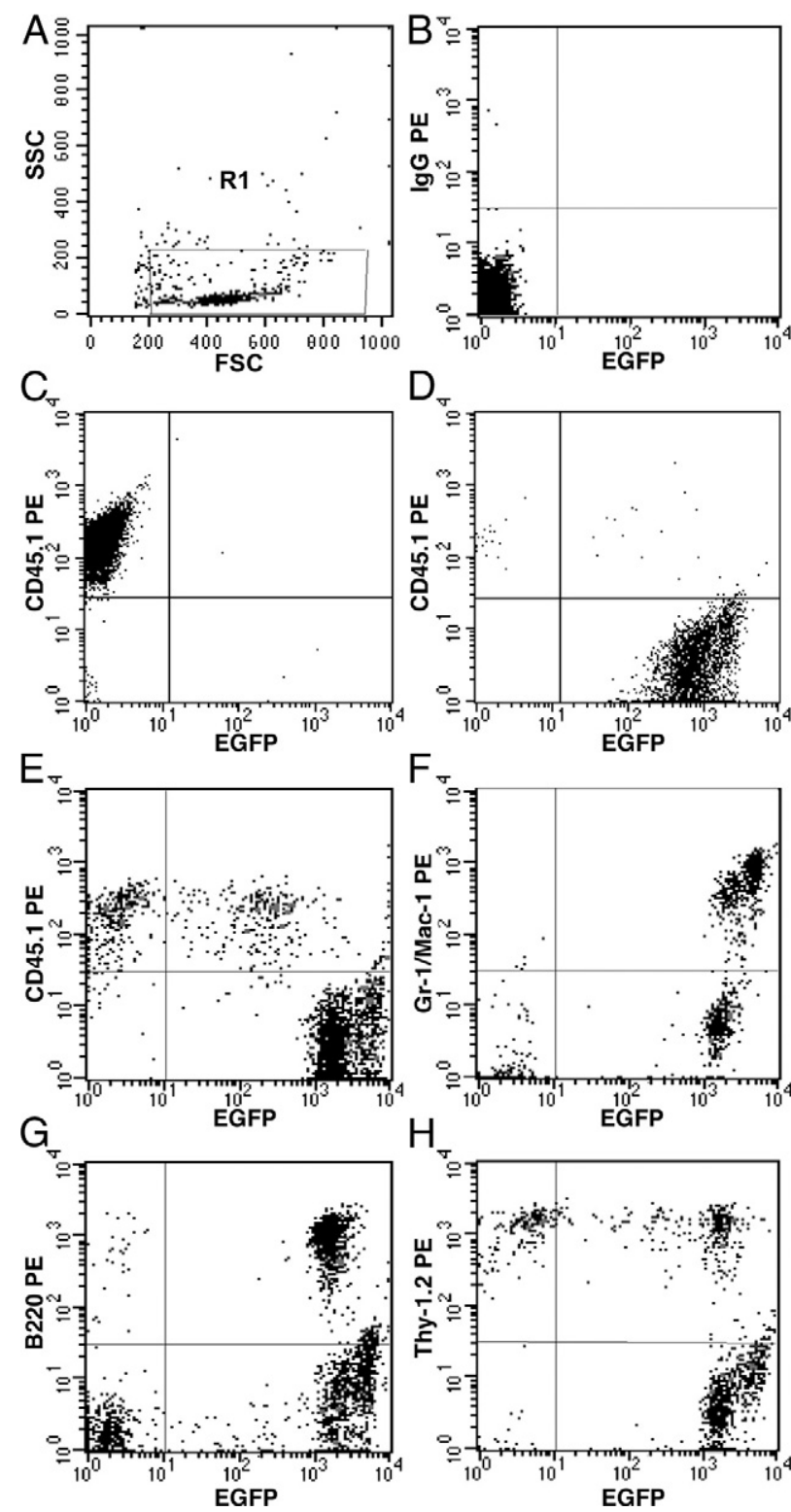

Figure 1. Multilineage engraftment. Panel A shows forward and side scatter gate (R1), B shows isotype control for CD 45.1 staining, and $\mathbf{C}$ and $\mathbf{D}$ show positive control for CD45.1 staining and EGFP expression, respectively. A representative analysis of peripheral blood cells from a clonally engrafted mouse 2 months after transplantation shows that $\mathrm{EGFP}^{+}$donor cells represented $93.58 \%$ of total nucleated cells $(\mathbf{E})$. $\mathrm{EGFP}^{+}$donor derived cells also represented $99.75 \%$ of granulocytes-macrophages $(\mathbf{F}), 98.49 \%$ of B-cells $(\mathbf{G})$, and $62.43 \%$ of T-cells $(\mathbf{H})$. 

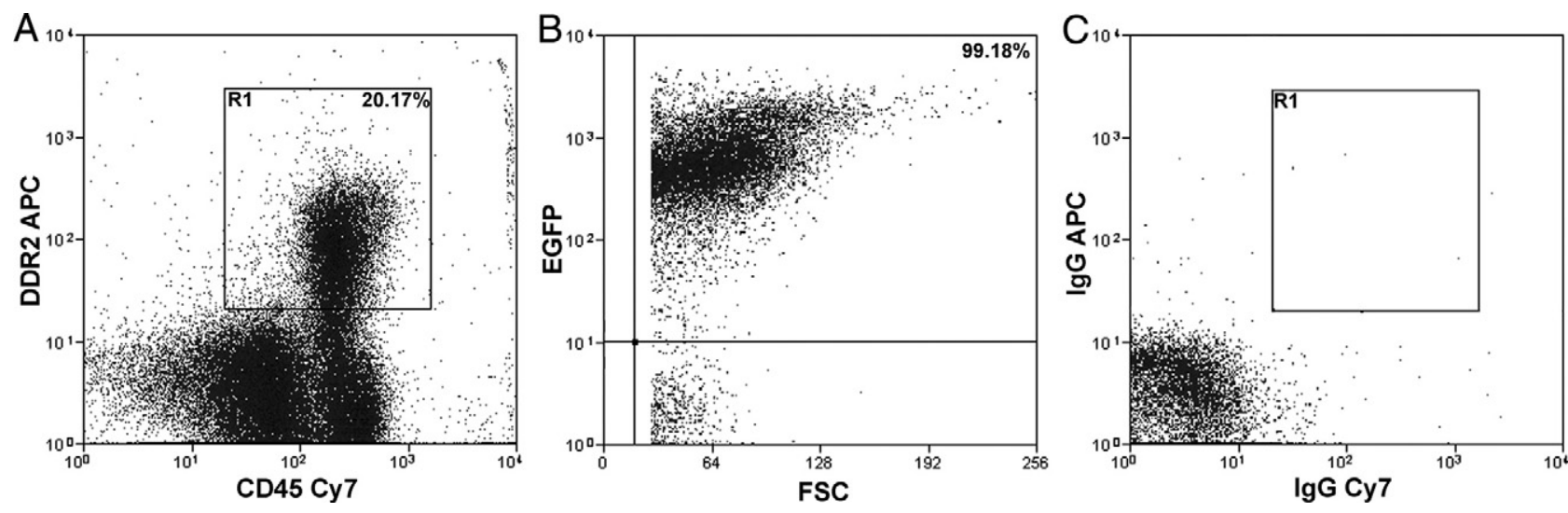

Figure 2. HSC origin of CFPs. Cytometric analysis of peripheral blood from a clonally engrafted mouse shows that the CFP population (R1, A) represents $\sim 20 \%$ of the total nucleated cells. Gating on the CD $45^{+} \mathrm{DDR}^{+}$(R1) cells shows that this population was $\sim 99 \% \mathrm{EGFP}^{+}(\mathbf{B})$. Total engraftment of EGFP ${ }^{+}$cells in the peripheral blood of this clonally engrafted mouse was $96.3 \%$. Isotype controls are shown in $\mathbf{C}$.

\section{Results}

\section{CFPs Are of HSC Origin}

Our previous in vitro studies identified a population of fibroblast precursors from the bone marrow and peripheral blood that were of HSC origin. ${ }^{21}$ When cultured, these precursors showed a decrease CD45 expression and an increase in expression of collagen I (Col I) and Discoidin Domain Receptor 2 (DDR2; a collagen receptor), demonstrating that differentiation of precursors to fibroblasts is accompanied by reciprocal expression of HSC and fibroblast markers. ${ }^{21}$ Our recent studies examining differentiation of human peripheral blood-derived fibroblast precursors showed similar results. ${ }^{38}$ In the present study, we first confirmed the HSC origin of fibroblast precursors in circulation using clonally engrafted mice. CFPs were defined as CD45+DDR2 ${ }^{+}$cells. ${ }^{21}$ Mice engrafted with clonal populations derived from a single $\mathrm{EGFP}^{+} \mathrm{HSC}$ were generated as described previously. ${ }^{21,23,36,39}$ Briefly, single Lin ${ }^{-}$Sca- $1^{+}{ }^{+} \mathrm{Ckit}^{+} \mathrm{CD} 34^{-}$side population cells were deposited individually and cultured for one week in the presence of SCF and G-CSF. Clones consisting of 20 or fewer cells were transplanted into lethally irradiated recipients. Two months after transplantation, multilineage engraftment was confirmed by flow cytometry (Figure 1, A-H). Mice exhibiting high levels of multilineage engraftment from a single HSC were then examined for the presence of HSC-derived EGFP ${ }^{+}$CFPs. Flow cytometric analysis of peripheral blood demonstrated that CFPs represented $\sim 20 \%$ of the total population (Figure 2A). Further analysis showed that $99.18 \%$ of the $\mathrm{CD}_{4} 5^{+} \mathrm{DDR}^{+}{ }^{+}$cells were EGFP ${ }^{+}$(Figure 2B), demonstrating that they were derived from the single-sorted $\mathrm{EGFP}^{+} \mathrm{HSC}$.

\section{CFPs Are Found in Vivo in the Tumor Stroma}

Our next studies showed that the HSC-derived CFPs observed in the peripheral blood incorporated into the LLC tumor microenvironment in vivo. For these studies, mice were engrafted with $\mathrm{EGFP}^{+}$whole bone marrow and LLC cells were delivered subcutaneously. Because our studies using clonally engrafted mice established the HSC origin of both the CFP (Figure 2, A-C) and a population of CAFs in both melanoma and LLC tumor models, ${ }^{23}$ mice used in these tracing studies were transplanted with un-manipulated bone marrow cells from $\mathrm{EGFP}^{+}$mice. This allowed for optimization of the number of HSC-derived cells for identification in tumor microenvironment. Resulting tumors were harvested at day 13 of growth $(\sim 1 \mathrm{~cm}$ in diameter) and either digested for flow cytometric analysis or processed for paraffin sections. When digested tumor was examined for the presence of $\mathrm{EGFP}^{+}$CFPs, the $\mathrm{EGFP}^{+} \mathrm{CD} 45^{+} \mathrm{DDR} 2^{+}$was found to compose $4.39 \%$ of the total tumor population.

Paraffin sections were then immunostained and imaged for the presence of $\mathrm{EGFP}^{+}$cells that expressed DDR2 (Figure 3, A-K). Analysis of high magnification images showed numerous EGFP ${ }^{+} \mathrm{DDR} 2^{+}$cells within the tumor microenvironment (Figure 3, B, and $\mathrm{G}-\mathrm{J}$ ). Several EGFP $^{+}$DDR2 ${ }^{+}$cells had an elongated, spindle-shape characteristic of fibroblasts (Figure $3, \mathrm{~A}, \mathrm{~B}, \mathrm{H}$, and $\mathrm{J}$, arrowheads). EGFP ${ }^{+} \mathrm{DDR} 2^{+}$cells with a rounded morphology, a shape consistent with that of a cell either in or just extravasated from circulation were also seen in the tumor stroma (Figure 3, A-D, G, I-K, arrows). $\mathrm{EGFP}^{+} \mathrm{DDR}^{+}{ }^{+}$cells with a rounded morphology were also found among red blood cells (asterisk) within the lumen of tumor vasculature (Figure 3, C, D, and K). To further characterize these HSC-derived cells, tumor sections were examined for the presence of $\mathrm{EGFP}^{+}$cells that expressed $\alpha$-smooth muscle actin ( $\alpha$ SMA, a protein whose expression is associated with myofibroblasts and CAFs) within the tumor microenvironment (Figure 4, A-F). High magnification images show that a subpopulation of EGFP ${ }^{+}$cells within the tumor microenvironment expressed $\alpha$ SMA (Figure 4, arrows). These findings are supported by our previous studies demonstrating that HSCs give rise to $\alpha \mathrm{SMA}^{+}$, collagen-expressing CAFs and perivascular cells. ${ }^{23}$ Together, these data suggest that HSC-derived CFPs arrive at the tumor via the circulation where they transition from a rounded circulating phenotype to more mature elongated fibroblast phenotype within the tumor stroma. 

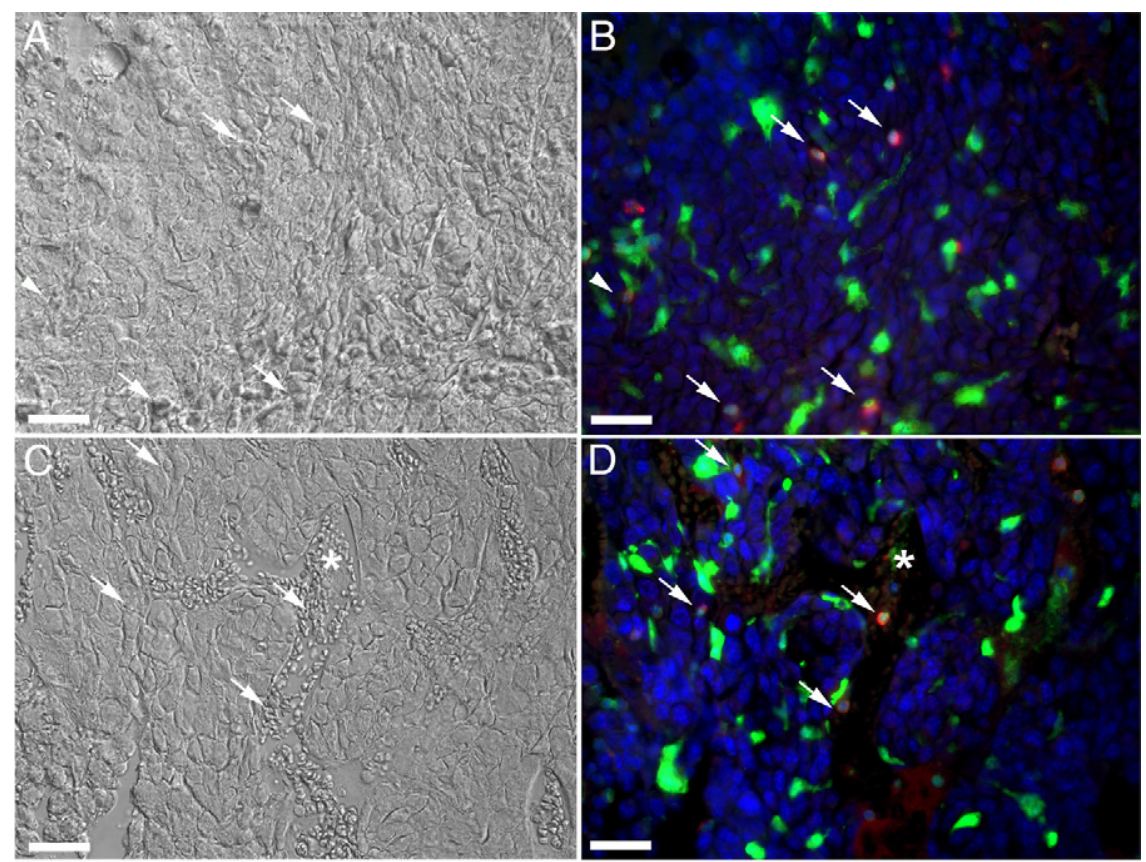

Figure 3. CFPs incorporate into tumor stroma in vivo. DIC and epifluorescence images of a day 13 sectioned LLC tissue from a mouse with hematopoietic engraftment of $92.1 \%$ showed numerous $\mathrm{EGFP}^{+}$(green) cells within the tumor stroma. When images taken in the green (EGFP), red (DDR2), and blue (Hoechst) channels were superimposed and analyzed along with corresponding DIC images, a subset of these EGFP ${ }^{+}$ cells were shown to express DDR2 (seen as yellow in fluorescent images) and have both a fibroblastic (arrowheads, A, B, H, J) and rounded morphology (arrows, $\mathbf{A}-\mathbf{D}, \mathbf{G}-\mathbf{K}$ ). In addition, $\mathrm{EGFP}^{+} \mathrm{DDR}^{+}$cells were found within

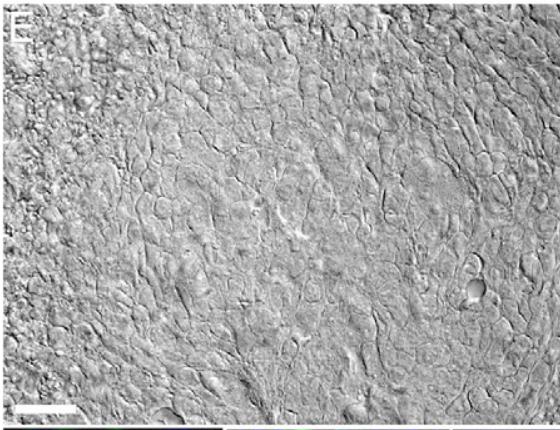

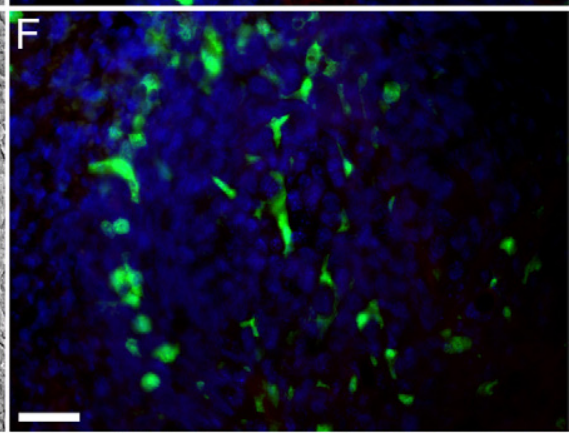
the tumor blood vessels, among the red blood cells (asterisks, $\mathbf{C}, \mathbf{D}$, and $\mathbf{K}$ ). High magnification images of $\mathrm{EGFP}^{+} \mathrm{DDR}^{+}$CFPs are shown in $\mathbf{G}-\mathbf{K}$. Panels $\mathbf{E}$ and $\mathbf{F}$ show DIC and fluorescent images, respectively, of tissue stained only with secondary antibodies and Hoechst. Hoechst staining is shown in blue. Dashed line in $\mathbf{K}$ indicates outline of vascular lumen. Scale bars: $25 \mu \mathrm{m}(\mathbf{A}-\mathbf{F}) ; 12.5 \mu \mathrm{m}(\mathbf{G}-\mathbf{K})$.
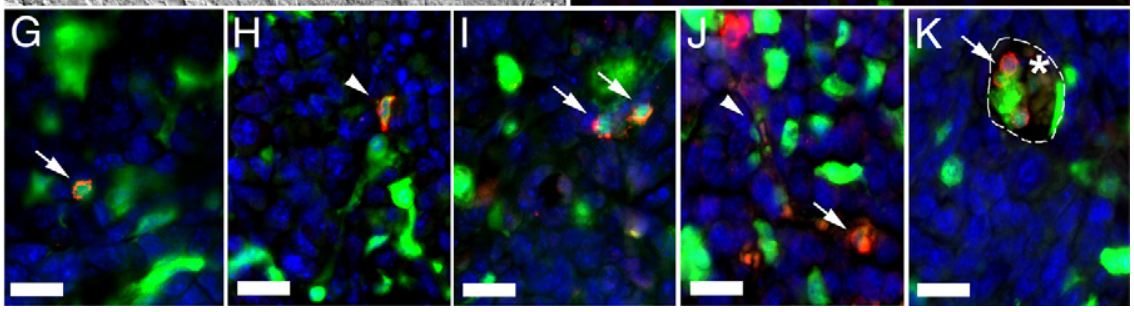

\section{CFPs Increase with Tumor Development}

We next examined the peripheral blood from normal and tumor bearing mice for the presence of CFPs. Normal mice were injected with LLC cells and tumors were allowed to progress to various time points $(\mathrm{d} 3, \mathrm{~d} 10$, and d17). Flow cytometric analysis of peripheral blood from LLC-bearing mice showed that the number of circulating $\mathrm{CD}_{4}{ }^{+} \mathrm{DDR} 2^{+}$cells increases with tumor development (Figure 5). To correlate the increase in CFPs seen in the peripheral blood with CFP participation in the tumor microenvironment, we analyzed cells from digested LLC tumors. In tumors that had been allowed to progress to maximum size $(1.5 \mathrm{~cm}$, day 21 post delivery), $8.15 \pm$ $2.35 \%(n=4)$ of the total tumor population was made up of $\mathrm{CD} 45^{+} \mathrm{DDR} 2^{+}$cells. This was almost double that seen at day 13 (4.39\%, as described above). These findings demonstrate that the number of CFPs in circulation in- crease with tumor burden and confirm that CFPs incorporate into developing tumors.

\section{CFPs Cultured in Presence of Tumor-Conditioned Media Give Rise to Fibroblasts}

To demonstrate that CFPs were able to differentiate into fibroblasts in vitro in response to tumor, $\mathrm{CD} 45^{+} \mathrm{DDR} 2^{+}$ cells were sorted from the peripheral blood of normal mice and cultured in the presence of conditioned medium from Lewis lung carcinoma cells (LLC-CM) to mimic tumor microenvironment (Figure 6). At the end of the 7-day culture period, cells were fixed and imaged using DIC microscopy to visualize the morphology of cells. Morphological analysis showed that differentiation into 

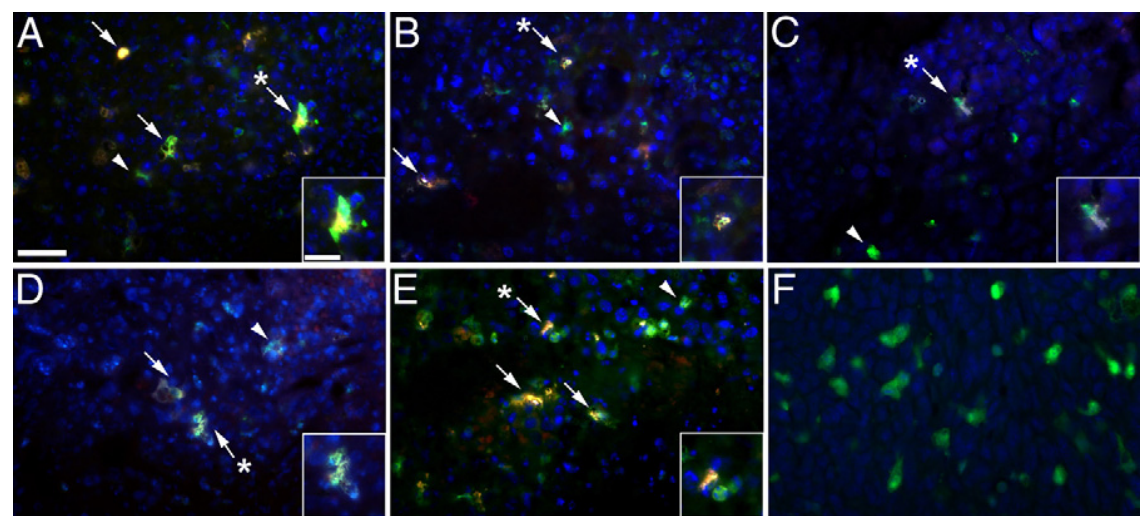

Figure 4. $\mathrm{EGFP}^{+}$cells express $\alpha \mathrm{SMA}$ in the tumor microenvironment. Paraffin sections from LLC tumor harvested at day 13 of growth were immunostained with antibodies to $\alpha$ SMA. Superimposed epifluorescence images $(\mathbf{A}-\mathbf{E})$ shows multiple $\mathrm{EGFP}^{+}$(green) cells within the tumor stroma that expressed $\alpha$ SMA (red), seen as yellow (arrows). $\mathrm{EGFP}^{+}$cells that did not express $\alpha$ SMA were also found (arrowheads). Insets in each Panel show high magnification images of $\mathrm{EGFP}^{+} \alpha \mathrm{SMA}^{+}$cells (indicated in lower magnification images by asterisks). Panel $\mathbf{F}$ shows an image of tissue stained only with secondary antibodies and Hoechst. Hoechst staining is shown in blue. Scale bars: $25 \mu \mathrm{m}(\mathbf{A}-\mathbf{F}) ; 12.5 \mu \mathrm{m}$ (insets).

fibroblasts, ie, elongated, spindle-shaped cells, is hastened by LLC-CM (Figure 6, C and D) relative to control media (Figure 6A) or media containing mouse serum (Figure 6B), which was shown to support fibroblast growth from stem/progenitor cells in 14 to 28 days. ${ }^{21}$ To demonstrate that cells with morphological characteristics of fibroblasts expressed proteins associated with fibroblasts, cultured cells were stained with antibodies to collagen I (Col I, a matrix molecule that is produced by activated fibroblasts), $\alpha \mathrm{SMA}$, and vimentin (an intermediate filament protein associated with fibroblasts) (Figure 7, A-F). These findings demonstrate that tumor-derived factors promote the differentiation of CD $45^{+} \mathrm{DDR} 2^{+}$CFPs to fibroblasts.

\section{CFPs Preferentially Migrate in Response to Tumor-Conditioned Media}

To begin to determine the mechanism by which HSCderived CFPs traffic to tumor, migration assays were conducted. Transwell assays were first conducted using freshly isolated nucleated peripheral blood cells from normal mice. Quantitative analysis showed that a population of cells preferentially migrated in response to LLC-CM (LLC-CM, $16.10 \pm 6.49 \%$ cells; control, $4.67 \pm$ $2.87 \%$ cells; $P \leq 0.05, n=3$ replicates, 4 mice per experiment). To determine whether CFPs were the cells

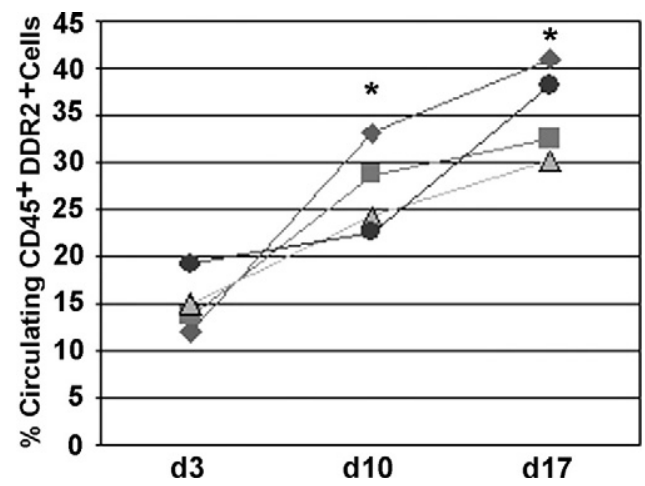

Figure 5. $\mathrm{CD} 45^{+} \mathrm{DDR} 2^{+}$cells increase with tumor burden. Percentages of $\mathrm{CD} 45^{+} \mathrm{DDR} 2^{+}$cells in peripheral blood of tumor-bearers were compared at days 3, 10, and 17. Each line represents an experiment and each point represents one mouse. Analysis shows a significant increase in \% CFPs as tumor size increased: day $3(15.0 \pm 3.1)$, day 10 (27.2 \pm 4.6$)$, day $17(35.5 \pm$ 5.0). ${ }^{*} P \leq 0.05$ as compared with day $3, n=4$. responsible for migration seen in response to LLC-CM, $\mathrm{CD}_{4} 5^{+} \mathrm{DDR} 2^{+}$CFPs were sorted from peripheral blood of normal mice (Figure 8, A and B) and analyzed in transwell assays. The percentage of migrating cells responding to LLC-CM (43.87 $\pm 13.3 \%$ cells; $n=11)$ was higher than the percentage of cells responding to control medium (26.6 $\pm 9.6 \%$ cells; $n=6$ ), demonstrating that sorted CFPs preferentially migrate in response to LLC-CM (Figure 8C, $P=0.02$ ). Control MLE-12 cells showed no preferential migration in response to LLC-CM $(P=0.39 ; n=4)$.

\section{CFPs Are of the Monocyte Lineage}

Based on our data demonstrating that CFPs were able to respond to chemotactic signals, a characteristic associated with the monocyte, and data from other groups suggesting a close relationship between the fibroblast and monocyte lineages, ${ }^{26,40,41}$ we next sought to define the lineage origin of the HSC-derived CFP. For these studies, the CD $45^{+}$DDR2 ${ }^{+}$population was analyzed for expression of markers associated with the monocyte lineage using multiparameter flow cytometry. These studies showed that $71.22 \%$ to $79.92 \%$ of $\mathrm{CD} 45^{+} \mathrm{DDR} 2^{+}$cells expressed Mac1 (CD11b). Further analysis showed that
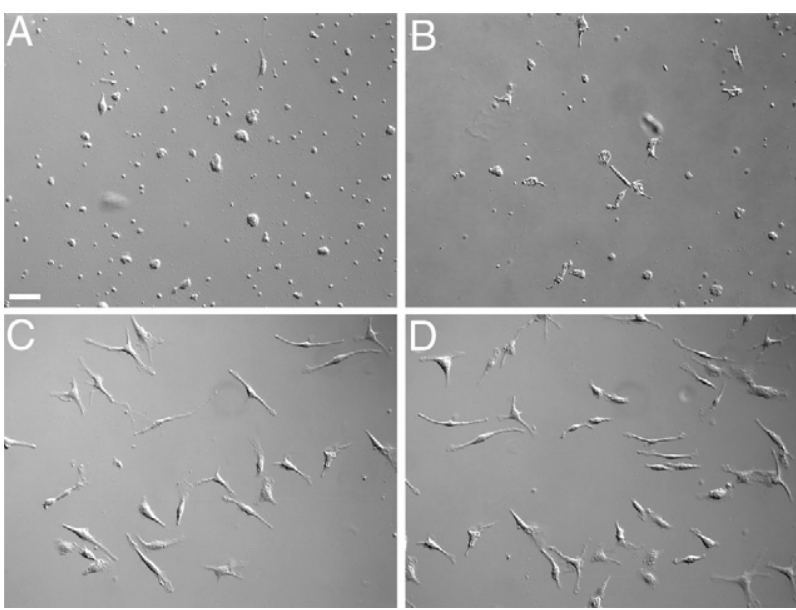

Figure 6. CFPs give rise to fibroblasts in vitro. Sorted CD $45^{+} \mathrm{DDR} 2^{+} \mathrm{CFPs}$ cultured in the presence of LLC-CM gave rise to fibroblasts $(\mathbf{C}$ and $\mathbf{D})$ earlier than those cultured in control media (A) or media containing mouse serum (B). Images were taken at 7 days of culture. Scale bar $=25 \mu \mathrm{m}$. 

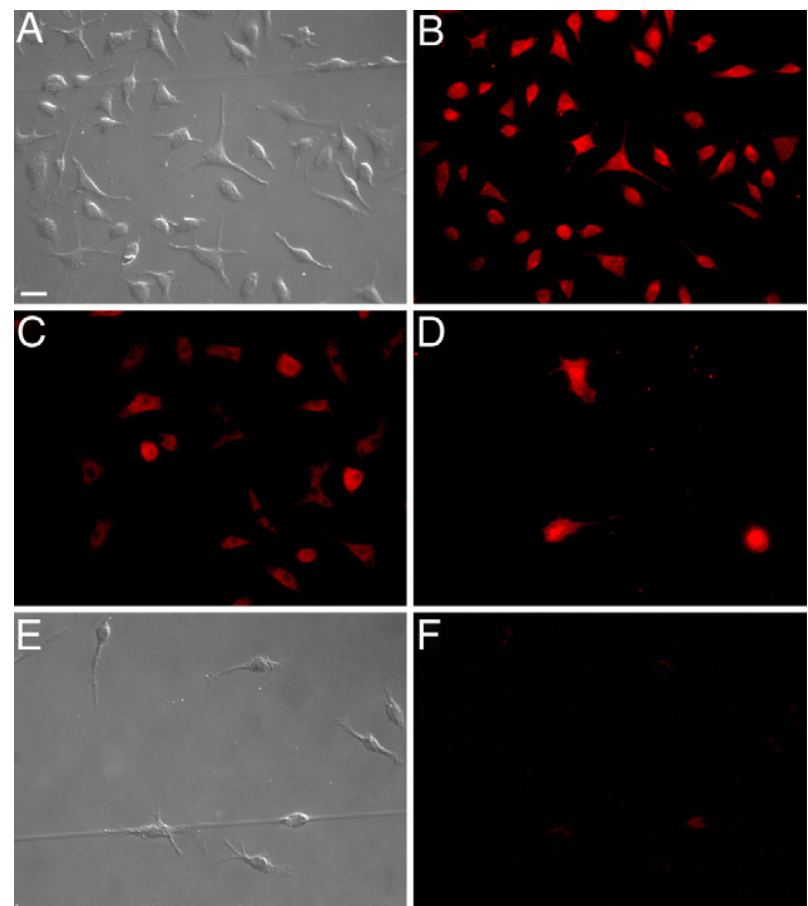

Figure 7. CFPs give rise to cells that express markers of fibroblasts. Sorted $\mathrm{CD} 45^{+} \mathrm{DDR}^{+}$CFPs cultured in the presence of LLC-CM gave rise to fibroblasts as indicated by morphology (A) and expression of Col I (B), vimentin $(\mathbf{C})$, and $\alpha$ SMA (D). Panels $\mathbf{E}$ and $\mathbf{F}$ show control fibroblasts stained with secondary antibodies only. Scale bar $=25 \mu \mathrm{m}$.

this population was heterogeneous in its expression of Mac1 and F4/80, a marker that increases as monocytes mature to macrophages (Figure 9, A-D).

To test the ability of these subpopulations to give rise to fibroblasts in vitro, $\mathrm{CD} 45^{+} \mathrm{DDR} 2^{+} \mathrm{Mac}^{\text {hi }} \mathrm{F} 4 / 80^{+}$ (9.22\% of $\mathrm{CD} 45^{+} \mathrm{DDR} 2^{+}$cells), $\mathrm{CD} 45^{+} \mathrm{DDR} 2^{+} \mathrm{Mac}^{\text {hi }} \mathrm{F} 4 /$ $80^{-}\left(38.39 \%\right.$ of $\mathrm{CD} 45^{+} \mathrm{DDR} 2^{+}$cells $), \mathrm{CD} 45^{+} \mathrm{DDR} 2^{+}$ $\mathrm{Mac}^{\mathrm{lo}} \mathrm{F} 4 / 80^{-} \quad\left(3.09 \%\right.$ of $\mathrm{CD}^{-} 5^{+} \mathrm{DDR} 2^{+}$cells $)$, and $\mathrm{CD}_{4} 5^{+} \mathrm{DDR} 2^{+} \mathrm{Mac}^{\mathrm{lo}} \mathrm{F} 4 / 80^{+}\left(0.26 \%\right.$ of $\mathrm{CD}^{+} 5^{+} \mathrm{DDR} 2^{+}$ cells) cells were sorted (Figure 9B) and cultured in the presence of LLC-CM. The numbers of sorted cells in each subpopulation that gave rise to fibroblasts was calculated based on morphology daily over 14 days (Figure 9E). Mac1 $1^{\text {hi }}$ CFPs had significantly higher fibroblast growth than Mac- $1^{\mathrm{lo}}$, with $\sim 80 \%$ of the cells differentiating to fibroblasts within two weeks in LLC-CM. Morphological analysis at day 14 of culture showed that cells with high expression of Mac-1 had the greatest fibroblast growth per well and that expression of F4/80 was not a significant determinant of fibroblast potential (Figure 9, $\mathrm{F}-\mathrm{H}) . \mathrm{CD}_{4} 5^{+} \mathrm{DDR} 2^{+} \mathrm{Mac} 1^{\mathrm{lo}} \mathrm{F} 4 / 80^{+}$cells, which represented $0.26 \%$ of the $C D 45^{+}$DDR2 ${ }^{+}$population, showed no cells by the end of the culture period and were not used for subsequent quantitative or immunohistochemical studies. Staining with antibodies to Col I and $\alpha$-SMA demonstrated that cells in each sorted population were able to express Col1 to some degree, with cells from $\mathrm{Mac}^{\text {hi }}$ populations showing greatest Col I production. However, the numbers of cells with a mature phenotype, indicated by an elongated morphology and expression of $\mathrm{Col} I$ and $\alpha$-SMA, were greater in the
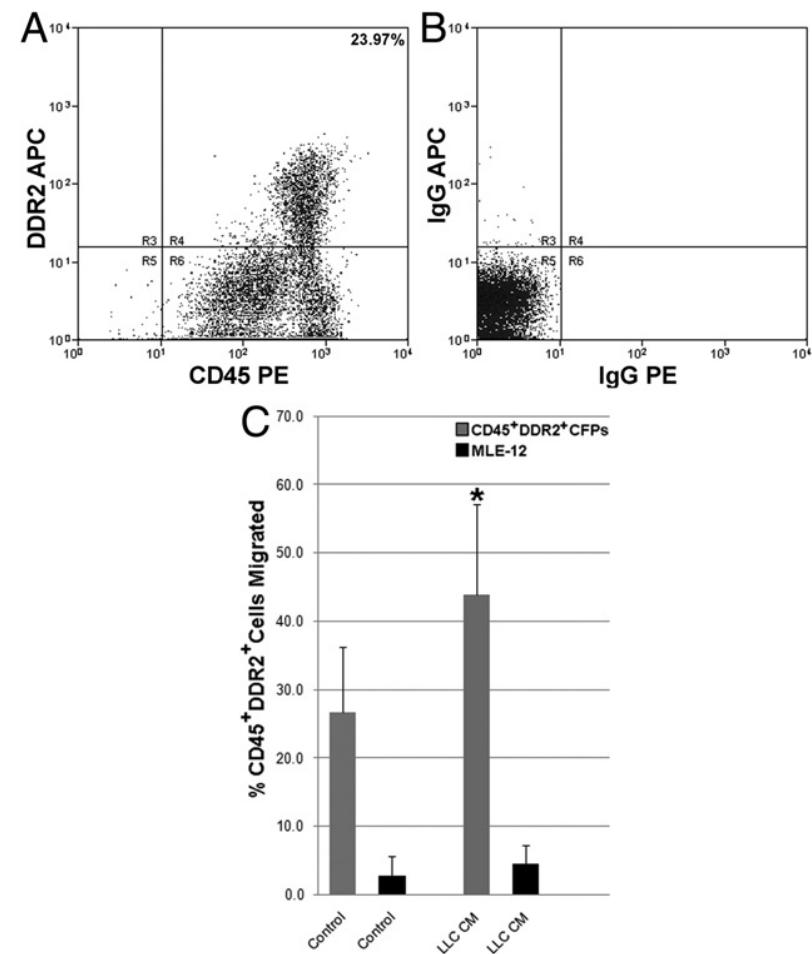

Figure 8. Sorted CFPs migrate toward tumor-CM. Flow cytometric analysis of peripheral blood identified a population of CD $45^{+}$DDR2 ${ }^{+}$CFPs $(23.97 \%, \mathbf{A})$. Panel $\mathbf{B}$ shows isotype control. When sorted and placed into transwell culture (Panel C), CD $45^{+}$DDR2 ${ }^{+}$CFPs (gray bars) showed a significant increase $\left({ }^{*} P=0.02\right)$ in the percentage of cells that migrated in response to LLC-CM $(43.87 \pm 13.3 \%$ cells; $n=11)$ relative to control media $(26.6 \pm 9.6 \%$ cells; $n=6$ ). Control MLE-12 cells (black bars) showed no preferential migration in response to LLC-CM $(P=0.39 ; n=4)$.

cultures of cells sorted based on high expression of Mac-1 (Figure 9, I-P).

To examine the potential of $\mathrm{CD} 45^{+} \mathrm{DDR} 2^{+}$cells based on Mac1 expression at the level of the single cell, single cells from each population were sorted into individual wells of a 96-well culture plate and cultured in the presence of LLC-CM for 7 days. Calculation of the number of fibroblasts based on morphology showed that $84 \%$ of CD $45^{+}$DDR $2^{+}$Mac1 $^{\text {hi }}$ cells (42/50 wells) were able to give rise to fibroblasts within 7 days. Cultured CD $45^{+}$ DDR2 ${ }^{+}$Mac $^{\text {lo }}$ cells resulted in few fibroblasts (8\%; 4/50 wells). Together these studies suggest that the CD45 DDR2 ${ }^{+}$Mac $^{\text {hi }}$ CFP population represents an immature circulating fibroblast precursor that is derived from the monocyte and can give rise to fibroblasts in the presence of tumor-CM.

To further confirm that CFPs were of monocyte origin, sorted $\mathrm{CD} 45^{+} \mathrm{DDR}^{+}$cells were cultured for 11 days in the presence of exogenous M-CSF, a cytokine that is known to regulate the maturation of the monocyte lineage and whose increased levels has been associated with chronic diseases and cancer (reviewed $\mathrm{in}^{42}$ ). Based on morphology and immunostaining with antibodies to Col I and $\alpha$ SMA, M-CSF was shown to promote differentiation of sorted CFPs when compared with 10\%FBS/DMEM (control) or 10\% FBS/10\% mouse serum/DMEM (Figure $10, A-J)$. M-CSF-induced differentiation was even more robust than that seen when cells were cultured in 

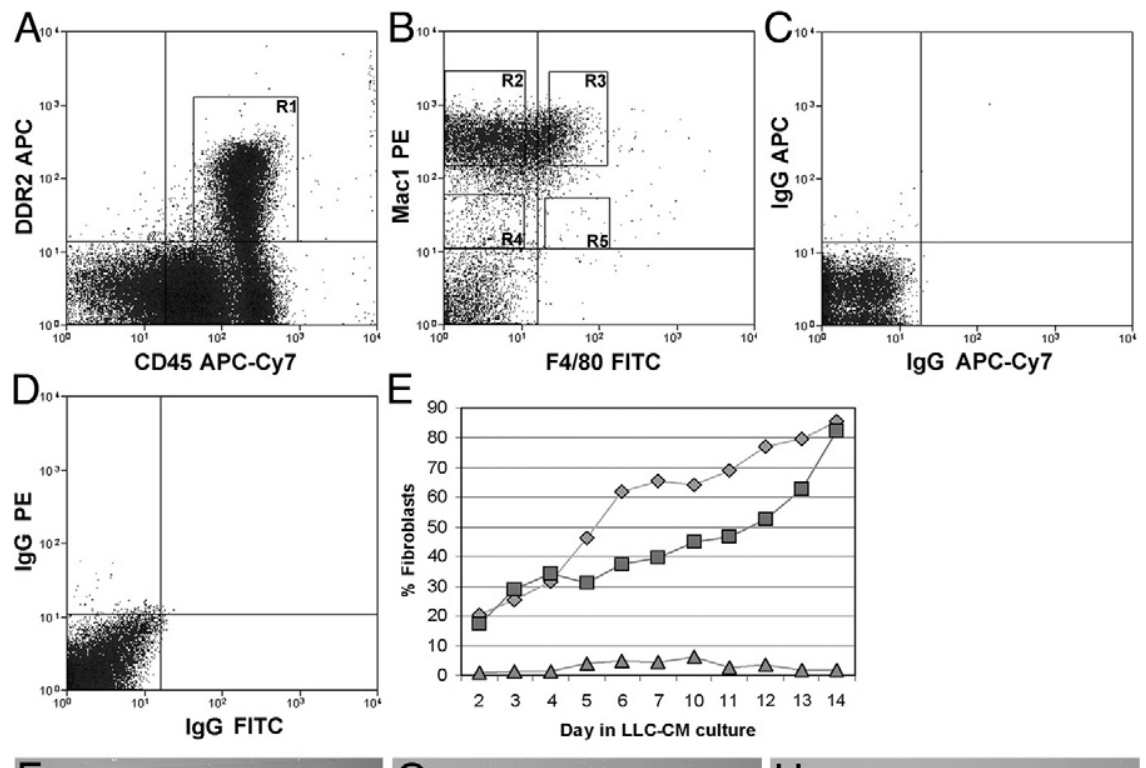

Day in LLC-CM culture
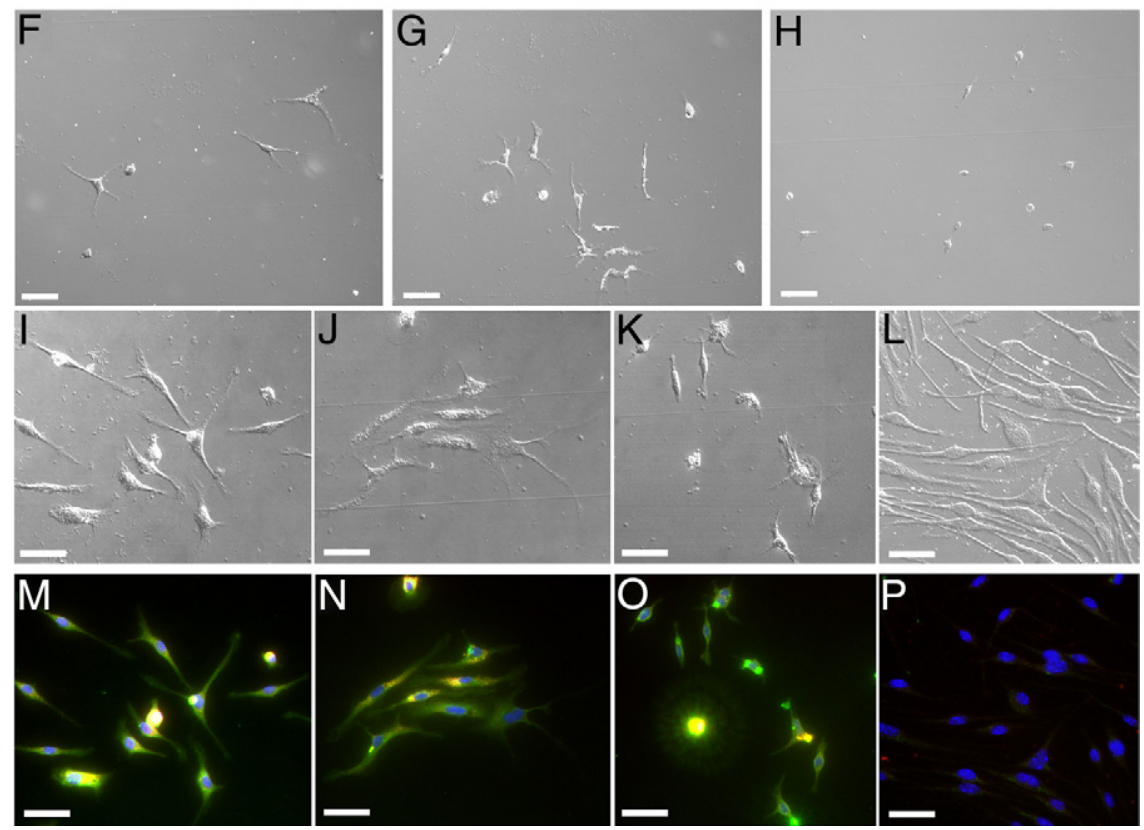

LLC-CM (Figure 10, compare panels E, F and G, H). ELISA analyses also showed that LLC-CM contained M-CSF $\left(1 \times 10^{5}\right.$ LLC cells produced $95.13 \mathrm{pg} / \mathrm{ml} \mathrm{M}$ CSF), suggesting that M-CSF may play a role in the differentiation of CFPs to mature carcinoma-associated fibroblasts.

\section{CFPs Express CCR2, Migrate in Response to Tumor-CM and Migration is MCP1-Dependent}

We next investigated the mechanism by which CFPs from the peripheral blood traffic to tumor. Given the shared lineage between CFPs and monocytes, we first examined LLC cell production of monocyte-associated chemokines including CXCL12 (stromal-derived factor-1), CCL21 (secondary lymphoid chemokine), and MCP1/CCL2 (monocyte chemoattractant protein 1; MCP1). ELISA for chemokine production by LLC cells showed that LLC-CM contains MCP1 in a cell concentration-dependent manner $\left(1 \times 10^{5}\right.$ LLC cells produced $\left.2.21 \mathrm{ng} / \mathrm{ml} \mathrm{MCP} 1\right)$, but not stromal-derived factor- $1 \alpha$ or secondary lymphoid chemokine.

Flow cytometric analysis using a MoFlo cell sorter for low incidence populations showed that $\sim 0.5$ to $1 \%$ (mean $0.74 \% \pm 0.21 \%$ ) of CFPs express CCR2, the MCP1 chemokine receptor (Figure 11, A, B). To confirm that the $\mathrm{CD}_{4} 5^{+} \mathrm{DDR} 2{ }^{+} \mathrm{CCR} 2{ }^{+}$population identified was not an artifact of flow cytometry, the $\mathrm{CD} 45^{+} \mathrm{DDR} 2^{+} \mathrm{CCR} 2^{-}$and $\mathrm{CD}_{4} 5^{+} \mathrm{DDR} 2{ }^{+} \mathrm{CCR} 2^{+}$populations were sorted (see gates, Figure 11C) and analyzed either by flow cytometry for purity or by qPCR. Flow cytometric analysis showed that $99.86 \%$ of the sorted $\mathrm{CD} 45^{+} \mathrm{DDR} 2^{+} \mathrm{CCR} 2^{-}$cells were negative for CCR2 expression (Figure 11D). Analysis by qPCR showed that the CCR2 message was significantly higher in the 

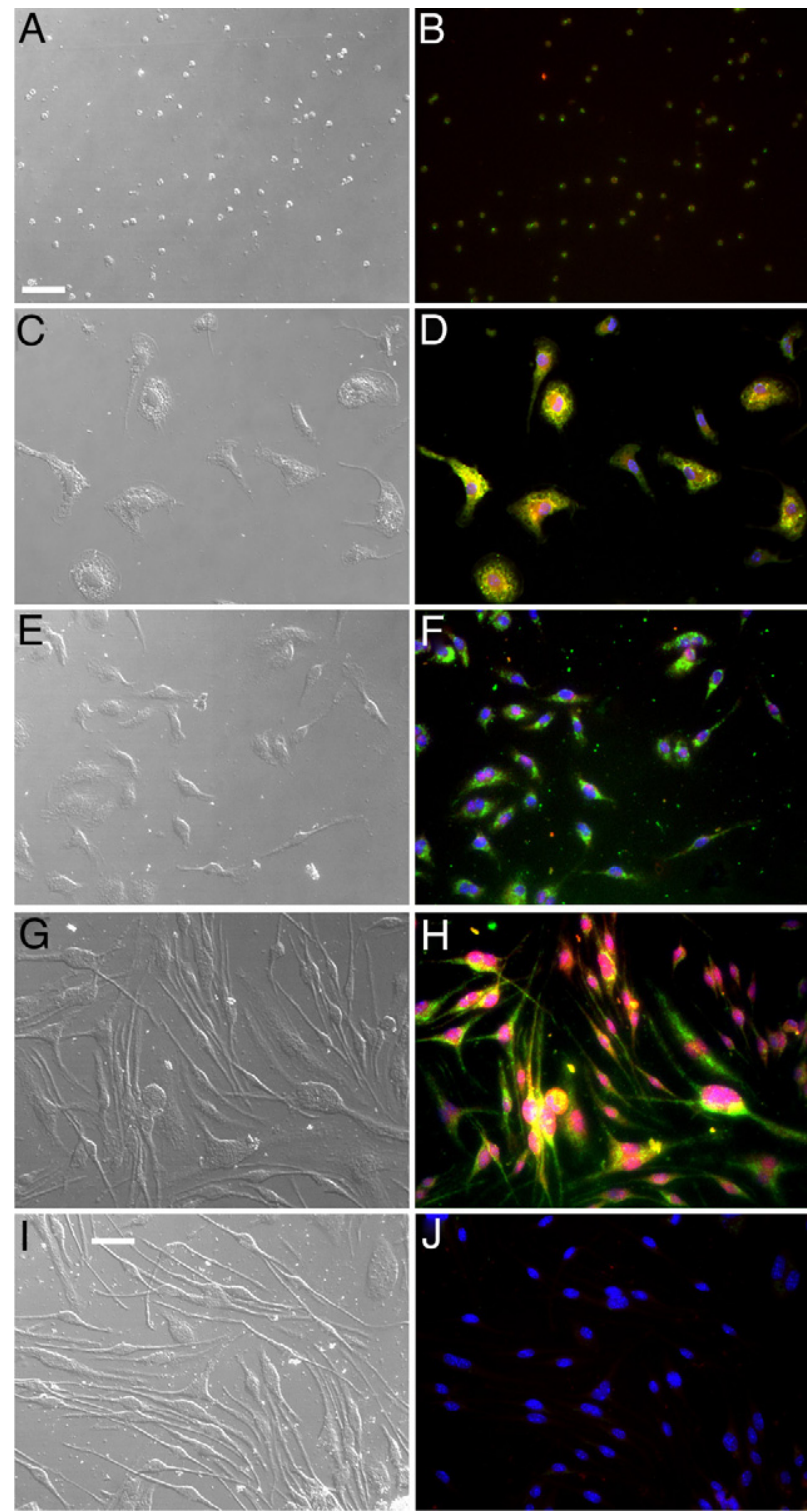

Figure 10. M-CSF promotes CFP differentiation. Sorted CFPs (CD $45^{+}$ $\mathrm{DDR}^{+}$) cultured in the presence of $10 \mu \mathrm{g} / \mathrm{ml}$ exogenous M-CSF $(\mathbf{G}, \mathbf{H})$ gave rise to fibroblasts earlier than those cultured in control media $(\mathbf{A}, \mathbf{B})$, media with mouse serum $(\mathbf{C}, \mathbf{D})$ or LLC-CM $(\mathbf{E}, \mathbf{F})$. Analysis of differentiation was based on morphology (DIC images, $\mathbf{A}, \mathbf{C}, \mathbf{E}, \mathbf{G}$ ) and expression of Col 1 (green) and $\alpha$ SMA (red). Panels $\mathbf{B}, \mathbf{D}, \mathbf{F}, \mathbf{H}$, and $\mathbf{J}$ show superimposition of images taken in the green ( $\mathrm{Col} \mathrm{I})$, red $(\alpha \mathrm{SMA})$ and blue (Hoechst) channels. Yellow indicates expression of both Coll and $\alpha$ SMA. In some cases, superimposition of $\alpha$ SMA expression and Hoechst images resulted in nuclei that appeared pink (D, F, H). Panels $\mathbf{I}$ and $\mathbf{J}$ show DIC and fluorescent images of tissue stained only with secondary antibodies and Hoechst (blue). Scale bar $=25 \mu \mathrm{m}$.

$\mathrm{CD} 45^{+} \mathrm{DDR} 2^{+} \mathrm{CCR} 2^{+}$population (mean $1.58 \pm 0.18$ ) as compared with the $\mathrm{CD} 45^{+} \mathrm{DDR} 2^{+} \mathrm{CCR} 2^{-}$population (0.88 $\pm 0.13 ; P=0.03)$. To determine whether CCR2expressing CFPs could migrate in response to LLC-CM, peripheral blood $\mathrm{CD}_{4} 5^{+} \mathrm{DDR} 2^{+} \mathrm{CCR} 2^{+}$cells were placed into transwells. Results showed that CD $45^{+} \mathrm{DDR} 2^{+}$ $\mathrm{CCR}^{+}$cells migrated in response to LLC-CM $(85 \%$ cells) as compared with control media (30\% cells). Sorted $\mathrm{CD} 45^{+} \mathrm{DDR} 2^{+} \mathrm{CCR} 2^{+}$cells were also shown to give rise to fibroblasts, based on morphology, in response to LLC-CM (data not shown).
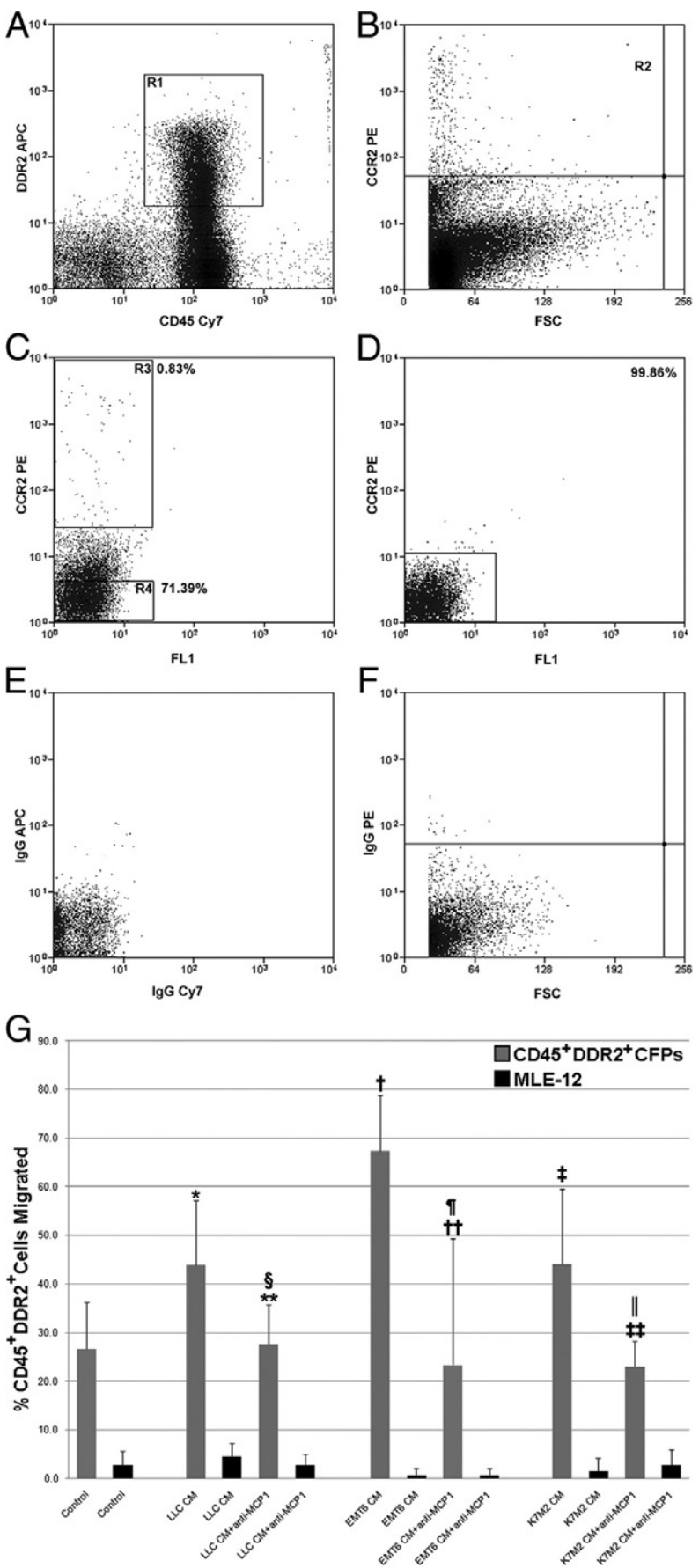

Figure 11. CFP migration to tumor is dependent on MCP1. A representative image from flow cytometric analysis of peripheral blood showing that the percentage of circulating $\mathrm{CD} 45^{+} \mathrm{DDR} 2^{+}$cells $(\mathrm{R} 1, \mathbf{A})$ expressing CCR2 $(\mathrm{R} 2, \mathbf{B})$ is $0.83 \%(\mathrm{R} 3, \mathbf{C})$. Panel $\mathbf{C}$ also shows the gates used to isolate $\mathrm{CD} 45^{+} \mathrm{DDR} 2^{+} \mathrm{CCR} 2^{+}$(R3) and $\mathrm{CD} 45^{+} \mathrm{DDR} 2^{+} \mathrm{CCR} 2^{-}$(R4) populations for flow cytometry or qPCR. Reanalysis of CCR2 expression in the $\mathrm{CD} 45^{+} \mathrm{DDR} 2^{+} \mathrm{CCR} 2^{-}$cells showed that this population was $99.86 \%$ pure (D). Isotype controls are shown in $\mathbf{E}$ and $\mathbf{F}$. Sorted CD $45^{+}$DDR2 $2^{+}$CFPs (gray bars) or MLE-12 control cells (black bars) were placed into transwell assays in the presence of control media (DMEM 10\% FBS), or tumor-CM (ie, LLC-CM, EMT6$\mathrm{CM}$, or K7M2-CM) with or without the addition of neutralizing anti-MCP1 antibody (G). Increased migration of sorted CFPs was seen in response to LLC-CM ( $\left.{ }^{*} P=0.02\right)$, EMT6-CM $\left({ }^{\dagger} P=0.00003\right)$, and K7M2-CM $\left({ }^{\ddagger} P=0.02\right)$ as compared with control media. Addition of neutralizing anti-MCP1 antibody to tumor-CM significantly reduced migration as compared with tumor-CM-induced migration of CFPs (LLC$\mathrm{CM}+$ anti-MCP1, ${ }^{\circledR} P=0.03$; EMT6-CM+anti-MCP1, ${ }^{\text {"I }} P=0.02 ; \mathrm{K} 7 \mathrm{M} 2-\mathrm{CM}+$ antiMCP1, $\left.\|_{P}=0.04\right)$. CFP migration in the presence of tumor-CM and neutralizing anti-MCP1 antibody was at $(P \geq 0.05$, *wfor LLC; \#for K7M2) or below $(P \leq 0.05$, "for EMT6) control. No significant migration was seen with MLE-12 cells under any condition $(P \geq 0.05)$. 

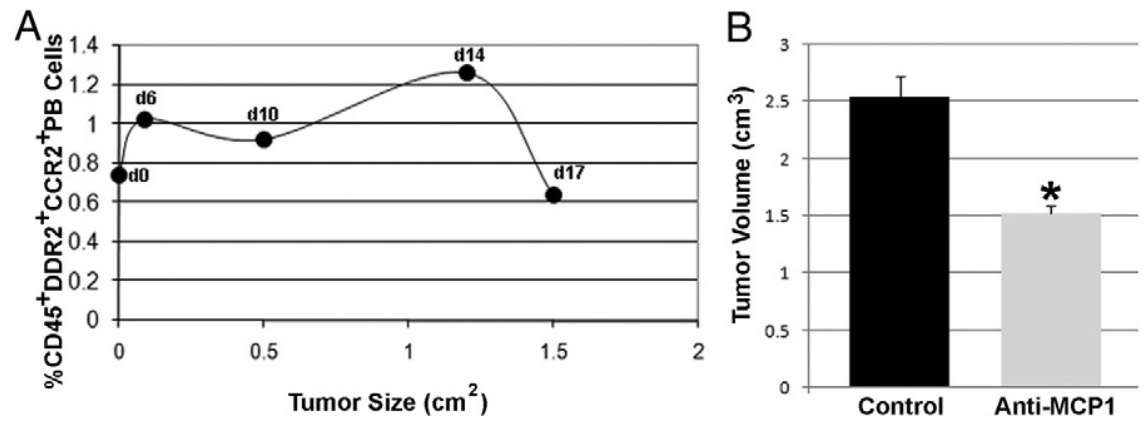

Figure 12. Inhibition of $\mathrm{MCP} 1$ decreases tumor volume. The $\mathrm{CD} 45^{+} \mathrm{DDR} 2^{+} \mathrm{CCR} 2^{+}$subset of CFPs in tumor-bearing mice was shown to increase as tumors increased in size (A), with the percentage in circulation peaking at day 14 of tumor growth $\left(1.2 \mathrm{~cm}^{2}\right)$. Panel B shows that delivery of anti-MCP1 neutralizing antibody to LLC-tumor bearing mice resulted in a significant $\left({ }^{*} P=0.02, \mathbf{B}\right)$ decrease in tumor volume $\left(\mathrm{cm}^{3}\right)$ from $2.54 \pm 0.18$ to $1.52 \pm 0.07$ at day 18 of tumor growth.
The effects of inhibiting MCP1 produced by tumor on CFP migration were then examined in vitro. CFPs were placed into transwell culture plates with control media, tumor-CM, or tumor-CM with the addition of MCP1 neutralizing antibody. Tumor-CM was harvested from the LLC, EMT-6 (murine mammary carcinoma) and K7M2 (murine osteosarcoma) tumor cell lines, all of which have been shown to produce MCP1 (data above and references $^{43,44}$ ). Analysis showed that exposure to conditioned media from each tumor line resulted in preferential migration of CFPs when compared with response of CFPs to control media (Figure 11G, $P \leq 0.05$ ). The addition of MCP1 neutralizing antibody to LLC-CM, EMT-6-CM, or $\mathrm{K} 7 \mathrm{M} 2-\mathrm{CM}$ resulted in significant decrease in migration of sorted CFPs, when compared with tumor-CM alone (Figure $11 \mathrm{G}, P \leq 0.05$ ). Inhibition of MCP1 reduced migration of CFPs to percentages at (Figure 11G, $P \geq 0.05$ ) or below (Figure 11G, $P \leq 0.05$ ) control levels. Together, these findings suggest that tumor production of MCP1 directs migration of HSC-derived CFPs in multiple tumor types.

\section{CCR2-Expressing CFPs Are Elevated in Tumor-Bearing Animals and MCP1 Inhibition Blocks Tumor Progression in Vivo}

As with total CFPs, in vivo studies showed that the subpopulation of $\mathrm{CCR}^{+}$CFPs increased in the peripheral blood of LLC-bearing mice as tumor increased in size from $0.0 \mathrm{~cm}^{2}$ (day 0) to $1.2 \mathrm{~cm}^{2}$ (day 14) (Figure 12A), with the highest percentage of $\mathrm{CD} 45^{+} \mathrm{DDR} 2^{+} \mathrm{CCR} 2^{+}$ cells seen in the peripheral blood at 14 days of growth. Subsequently, when tumors reached a maximum size of $1.5 \mathrm{~cm}^{2}$ (day 17), the number of CFPs in circulation decreased to that of or below control animals, suggesting that CFPs contribute during tumor stromal formation. Flow cytometric analysis of digested cells from LLC tumors harvested at day 21 of growth showed that $1.10 \pm 0.16 \%(n=3)$ of cells within the digested tumor were $\mathrm{CD} 45^{+} \mathrm{DDR} 2^{+} \mathrm{CCR} 2^{+}$. This subpopulation was also shown to be EGFP ${ }^{+}$in tumors from engrafted mice $\left(0.78 \% \mathrm{EGFP}^{+} \mathrm{CD} 45^{+} \mathrm{DDR} 2^{+} \mathrm{CCR} 2^{+}\right)$, confirming their HSC origin.

To demonstrate the consequence of in vivo inhibition of MCP1 during tumor development, two groups of mice were injected with LLC cells ( $n=3$ per group). In the control group, tumors were allowed to progress normally and in the experimental group, neutralizing antibodies to MCP1 were delivered every other day after tumor cell delivery. Analysis of tumor volume at sacrifice (day 18) showed that mice receiving the MCP1 neutralizing antibodies had a significantly smaller tumor volume (mean $1.52 \pm 0.07 \mathrm{~cm}^{3}$ ) when compared with nontreated cohorts (mean $\left.2.54 \pm 0.18 \mathrm{~cm}^{3}\right)(P=0.02)$ (Figure 12B).

\section{Discussion}

Multiple origins for CAFs have been suggested, including resident tissue fibroblasts, epithelial-to-mesenchymal transdifferentiation, and the bone marrow. Our previous studies, based on single HSC transplantation, demonstrated that HSCs give rise to a population of collagenproducing CAFs and perivascular cells in tumor stroma. ${ }^{23}$ In the present study, we examined the mechanisms by which these HSC-derived cells contribute to the tumor stroma. Using transplantation of a clonal population of cells derived from a single HSC, we establish that CFPs are of HSC origin. We found these HSC-derived cells both incorporated into the tumor stroma and circulating in the tumor vasculature in vivo, indicating that CFPs contribute to tumor via the circulation. We also showed that a population of these HSC-derived cells expressed $\alpha$ SMA, a marker of CAFs. In addition, the CFP population increased in the peripheral blood and tumor stroma with tumor burden. In vitro studies confirmed that sorted CFPs were able to give rise to mature fibroblasts/myofibroblasts that expressed collagen, vimentin, and $\alpha \mathrm{SMA}$ in response to tumor conditioned media. These findings are supported by our previous works demonstrating that differentiation of both mouse and human fibroblast precursors is accompanied by an increase in fibroblastic markers and a concomitant decrease in hematopoietic markers. ${ }^{21,38}$ Together, these findings demonstrate that HSC-derived CFPs are, at least, a contributing source of CAFs during tumor development.

We also sought to determine the lineage origin of HSCderived CFPs. Based on their HSC origin, ability to preferentially migrate and previous studies suggesting similarities between the fibroblast precursor, fibroblasts, and the monocyte, it was our hypothesis that the CFP represents a transitional phenotype from the monocytic lineage to the fibroblastic lineage with the ability to respond to and participate in solid tumor stromal formation. Our data show that the CFP represents a subpopulation of 
circulating monocytes that resides in the Mac $1^{\text {hi }}$ subset of peripheral blood cells. These findings also show that while $80 \%$ to $84 \%$ of sorted Mac $1^{\text {hi }}$ CFPs are able to give rise to fibroblasts in response to tumor, Mac $1^{\text {lo }}$ CFPs did not possess this potential to the same extent, suggesting that the CFP is derived from the monocyte rather than the monocyte precursor. The CFP was also shown to differentiate in the presence of M-CSF, a cytokine known to regulate the monocyte lineage, whose increased presence is associated with several chronic diseases and cancer (reviewed $\mathrm{in}^{42}$ ). Our finding of a monocyte lineage origin for HSC-derived CFPs is in agreement with others demonstrating that fibrocytes, which are a mesenchymal cell type in peripheral blood thought to be a source of fibroblasts, ${ }^{45}$ may differentiate from monocytes ${ }^{26,40,41}$ (reviewed in ${ }^{46,47}$ ).

Based on this demonstrated relationship between CFPs and monocytes and their ability to preferentially migrate in response to tumor, we examined the potential role of chemokines in the recruitment/homing of HSCderived CFPs to tumor. A subset of CFPs was shown to express functional CCR2, the chemokine receptor for MCP1, and inhibition of MCP1 produced by multiple tumor types (ie, LLC, EMT6, and K7M2) was shown to reduce CFP migration. We also found that the number of CFPs expressing CCR2 increased in the peripheral blood as tumor size increased. Based on tumor size, this period of active CFP recruitment and homing corresponded to the period of tumor growth in which the stromal component, including the vasculature was established. Together with our previous studies demonstrating an HSC origin for CAFs, myofibroblasts and perivascular cells, ${ }^{23}$ the present studies suggest that at least a portion of HSC-derived CFPs use the CCR2 chemokine receptor to home to tumor microenvironment to contribute to these populations. Finally, we demonstrate that disruption of normal MCP1/CCR2 signaling results in reduced tumor burden. While it is likely that systemic inhibition of MCP1 affected both the CFP and monocyte/macrophage populations, given our findings of shared lineage origin between CFPs and monocytes/macrophages, these findings suggest the therapeutic potential of targeting the MCP1/CCR2 axis during tumor development to alter tumor growth rate and/or limit tumor progression and metastasis.

\section{Acknowledgments}

We thank Dr. Makio Ogawa for his critical reading and assistance in the preparation of this manuscript, Ms. Liya Liu for assistance in tissue processing, Dr. Deanne Lathers for her assistance in ELISA preparations, and the staff of the Radiation Oncology Department of the Medical University of South Carolina in irradiation of mice. We also acknowledge the Hollings Cancer Center Flow Cytometry Core and specifically thank Dr. Haiqun Zeng for assistance in FACS sorting.

\section{References}

1. Orimo A, Weinberg RA: Stromal fibroblasts in cancer: a novel tumorpromoting cell type. Cell Cycle 2006, 5:1597-1601

2. Karnoub AE, Dash AB, Vo AP, Sullivan A, Brooks MW, Bell GW, Richardson AL, Polyak K, Tubo R, Weinberg RA: Mesenchymal stem cells within tumour stroma promote breast cancer metastasis. Nature 2007, 449:557-563

3. De Wever O, Mareel M: Role of tissue stroma in cancer cell invasion. J Pathol 2003, 200:429-447

4. Olumi AF, Grossfeld GD, Hayward SW, Carroll PR, Tlsty TD, Cunha GR: Carcinoma-associated fibroblasts direct tumor progression of initiated human prostatic epithelium. Cancer Res 1999, 59:5002-5011

5. Mishra PJ, Mishra PJ, Humeniuk R, Medina DJ, Alexe G, Mesirov JP, Ganesan S, Glod JW, Banerjee D: Carcinoma-associated fibroblastlike differentiation of human mesenchymal stem cells. Cancer Res 2008, 68:4331-4339

6. Mishra PJ, Mishra PJ, Glod JW, Banerjee D: Mesenchymal stem cells: flip side of the coin. Cancer Res 2009, 69:1255-1258

7. Roorda BD, ter Elst A, Kamps WA, de Bont ES: Bone marrow-derived cells and tumor growth: contribution of bone marrow-derived cells to tumor micro-environments with special focus on mesenchymal stem cells. Crit Rev Oncol Hematol 2009, 69:187-198

8. Selman M, Pardo A: Role of epithelial cells in idiopathic pulmonary fibrosis: from innocent targets to serial killers. Proc Am Thorac Soc 2006, 3:364-372

9. Radisky DC, Kenny PA, Bissell MJ: Fibrosis and cancer: do myofibroblasts come also from epithelial cells via EMT? J Cell Biochem 2007, 101:830-839

10. Trimboli AJ, Fukino K, de Bruin A, Wei G, Shen L, Tanner SM, Creasap N, Rosol TJ, Robinson ML, Eng C, Ostrowski MC, Leone G: Direct evidence for epithelial-mesenchymal transitions in breast cancer. Cancer Res 2008, 68:937-945

11. Ishii G, Sangai T, Oda T, Aoyagi $Y$, Hasebe $T$, Kanomata N, Endoh $Y$, Okumura C, Okuhara Y, Magae J, Emura M, Ochiya T, Ochiai A: Bone-marrow-derived myofibroblasts contribute to the cancer-induced stromal reaction. Biochem Biophys Res Commun 2003, 309:232-240

12. Friedenstein AJ, Chailakhjan RK, Lalykina KS: The development of fibroblast colonies in monolayer cultures of guinea-pig bone marrow and spleen cells. Cell Tissue Kinet 1970, 3:393-403

13. Luria EA, Panasyuk AF, Friedenstein AY: Fibroblast colony formation from monolayer cultures of blood cells. Transfusion 1971, 11:345-349

14. Pittenger MF, Mackay AM, Beck SC, Jaiswal RK, Douglas R, Mosca JD, Moorman MA, Simonetti DW, Craig S, Marshak DR: Multilineage potential of adult human mesenchymal stem cells. Science 1999, 284:143-147

15. Ryden M, Dicker A, Gotherstrom C, Astrom G, Tammik C, Arner P, Le Blanc K: Functional characterization of human mesenchymal stem cell-derived adipocytes. Biochem Biophys Res Commun 2003, 311:391-397

16. Mackay AM, Beck SC, Murphy JM, Barry FP, Chichester CO, Pittenger MF: Chondrogenic differentiation of cultured human mesenchymal stem cells from marrow. Tissue Eng 1998, 4:415-428

17. Johnstone B, Hering TM, Caplan Al, Goldberg VM, Yoo JU: In vitro chondrogenesis of bone marrow-derived mesenchymal progenitor cells. Exp Cell Res 1998, 238:265-272

18. Jaiswal N, Haynesworth SE, Caplan Al, Bruder SP: Osteogenic differentiation of purified, culture-expanded human mesenchymal stem cells in vitro. J Cell Biochem 1997, 64:295-312

19. Reyes M, Dudek A, Jahagirdar B, Koodie L, Marker PH, Verfaillie CM: Origin of endothelial progenitors in human postnatal bone marrow. J Clin Invest 2002, 109:337-346

20. Studeny M, Marini FC, Champlin RE, Zompetta C, Fidler IJ, Andreeff M: Bone marrow-derived mesenchymal stem cells as vehicles for interferon-beta delivery into tumors. Cancer Res 2002, 62:3603-3608

21. Ebihara $Y$, Masuya M, Larue AC, Fleming PA, Visconti RP, Minamiguch $\mathrm{H}$, Drake CJ, Ogawa M: Hematopoietic origins of fibroblasts: ii. in vitro studies of fibroblasts, CFU-F, and fibrocytes. Exp Hematol 2006, 34:219-229

22. Ogawa M, LaRue AC, Drake CJ: Hematopoietic origin of fibroblasts/ myofibroblasts: its pathophysiologic implications. Blood 2006, 108:2893-2896

23. LaRue AC, Masuya M, Ebihara Y, Fleming PA, Visconti RP, Minamiguchi 
H, Ogawa M, Drake CJ: Hematopoietic origins of fibroblasts: i. in vivo studies of fibroblasts associated with solid tumors. Exp Hematol 2006, $34: 208-218$

24. Lapidot T, Kollet O: The essential roles of the chemokine SDF-1 and its receptor CXCR4 in human stem cell homing and repopulation of transplanted immune-deficient NOD/SCID and NOD/SCID/B2m(null) mice. Leukemia 2002, 16:1992-2003

25. Burger JA, Kipps TJ: CXCR4: a key receptor in the crosstalk between tumor cells and their microenvironment. Blood 2006, 107:1761-1767

26. Abe R, Donnelly SC, Peng T, Bucala R, Metz CN: Peripheral blood fibrocytes: differentiation pathway and migration to wound sites. J Immunol 2001, 166:7556-7562

27. Phillips RJ, Burdick MD, Hong K, Lutz MA, Murray LA, Xue YY, Belperio JA, Keane MP, Strieter RM: Circulating fibrocytes traffic to the lungs in response to CXCL12 and mediate fibrosis. J Clin Invest 2004, 114:438-446

28. Kim CH, Broxmeyer HE: SLC/exodus2/6Ckine/TCA4 induces chemotaxis of hematopoietic progenitor cells: differential activity of ligands of CCR7, CXCR3, or CXCR4 in chemotaxis vs suppression of progenitor proliferation. J Leukoc Biol 1999, 66:455-461

29. Nesbit M, Schaider H, Miller TH, Herlyn M: Low-level monocyte chemoattractant protein-1 stimulation of monocytes leads to tumor formation in nontumorigenic melanoma cells. J Immunol 2001, 166 : 6483-6490

30. Moore BB, Kolodsick JE, Thannickal VJ, Cooke K, Moore TA, Hogaboam C, Wilke CA, Toews GB: CCR2-mediated recruitment of fibrocytes to the alveolar space after fibrotic injury. Am J Pathol 2005, 166:675-684

31. Okabe M, Ikawa M, Kominami K, Nakanishi T, Nishimune Y: 'Green mice' as a source of ubiquitous green cells. FEBS Lett 1997, 407:313-319

32. Goodell MA, Rosenzweig M, Kim H, Marks DF, DeMaria M, Paradis G, Grupp SA, Sieff CA, Mulligan RC, Johnson RP: Dye efflux studies suggest that hematopoietic stem cells expressing low or undetectable levels of CD34 antigen exist in multiple species. Nat Med 1997, 3:1337-1345

33. Matsuzaki Y, Kinjo K, Mulligan RC, Okano H: Unexpectedly efficient homing capacity of purified murine hematopoietic stem cells. Immunity 2004, 20:87-93

34. Ikebuchi K, Clark SC, Ihle JN, Souza LM, Ogawa M: Granulocyte colony-stimulating factor enhances interleukin 3-dependent proliferation of multipotential hemopoietic progenitors. Proc Natl Acad Sci USA 1988, 85:3445-3449
35. Osawa M, Hanada K, Hamada H, Nakauchi H: Long-term lymphohematopoietic reconstitution by a single CD34- low/negative hematopoietic stem cell. Science 1996, 273:242-245

36. Masuya M, Drake CJ, Fleming PA, Reilly CM, Zeng $H$, Hill WD Martin-Studdard A, Hess DC, Ogawa M: Hematopoietic origin of glomerular mesangial cells. Blood 2003, 101:2215-2218

37. Tomayko MM, Reynolds CP: Determination of subcutaneous tumor size in athymic (nude) mice. Cancer Chemother Pharmacol 1989, $24: 148-154$

38. Shirai K, Sera Y, Bulkeley W, Mehrotra M, Moussa O, LaRue AC, Watson DK, Stuart RK, Lazarchick J, Ogawa M: Hematopoietic stem cell origin of human fibroblasts: cell culture studies of female recipients of gender-mismatched stem cell transplantation and patients with chronic myelogenous leukemia. Exp Hematol 2009, 37:1464-1471

39. Hess DC, Abe T, Hill WD, Studdard AM, Carothers J, Masuya M, Fleming PA, Drake CJ, Ogawa M: Hematopoietic origin of microglial and perivascular cells in brain. Exp Neurol 2004, 186:134-144

40. Shao DD, Suresh R, Vakil V, Gomer RH, Pilling D: Pivotal advance: th-1 cytokines inhibit, and Th-2 cytokines promote fibrocyte differentiation. J Leukoc Biol 2008, 83:1323-1333

41. Haudek SB, Trial J, Xia Y, Gupta D, Pilling D, Entman ML: Fc receptor engagement mediates differentiation of cardiac fibroblast precursor cells. Proc Natl Acad Sci USA 2008, 105:10179-10184

42. Wei S, Lightwood D, Ladyman H, Cross S, Neale H, Griffiths M, Adams R, Marshall D, Lawson A, McKnight AJ, Stanley ER: Modulation of CSF-1-regulated post-natal development with anti-CSF-1 antibody. Immunobiology 2005, 210:109-119

43. Kurt RA, Baher A, Wisner KP, Tackitt S, Urba WJ: Chemokine receptor desensitization in tumor-bearing mice. Cell Immunol 2001, 207:81-88

44. Schiller KR, Zillhardt MR, Alley J, Borjesson DL, Beitz AJ, Mauro LJ: Secretion of MCP-1 and other paracrine factors in a novel tumor-bone coculture model. BMC Cancer 2009, 9:45

45. Schmidt M, Sun G, Stacey MA, Mori L, Mattoli S: Identification of circulating fibrocytes as precursors of bronchial myofibroblasts in asthma. J Immunol 2003, 171:380-389

46. Bellini A, Mattoli S: The role of the fibrocyte, a bone marrow-derived mesenchymal progenitor, in reactive and reparative fibroses. Lab Invest 2007, 87:858-870

47. Rosenberg HF: Cytokines and fibrocyte differentiation - altering the balance: an interview with Dr. Darrell Pilling. Interview by Helene F Rosenberg. J Leukoc Biol 2008, 83:1334-1335 